\title{
EL PROJECTE FUNDACIONAL DEL MONESTIR DE SANTA MARIA DE PEDRALBES I EL PALAU DE LA REINA ELISENDA DE MONTCADA A TRAVÉS DE DOS INVENTARIS DEL $1364^{1}$
}

\author{
PLANS FOR CONSTRUCTING THE MONASTERY \\ OF SANTA MARIA DE PEDRALBES AND THE PALACE OF \\ QUEEN ELISENDA OF MONTCADA, \\ AS GLEANED FROM TWO INVENTORIES FROM 1364
}

AnNa CASTELlano-TRESSERRA

Reial Monestir de Santa Maria de Pedralbes

Ajuntament de Barcelona

\begin{abstract}
Resum: Aquest treball pretén dur a terme una relectura de dos inventaris ja coneguts del Reial Monestir de Santa Maria de Pedralbes, redactats a la mort de la reina i de l'abadessa Francesca Saportella l'any 1364. La posada en comú dels dos textos, amb el suport d'altres documents i estudis complementaris, en el marc actual dels coneixements de què es disposa sobre l'evolució històrica i arquitectònica de l'indret, permet observar amb tota claredat que la fundació i configuració del conjunt inicial va respondre a un pla preconcebut en la seva globalitat, rere del qual s'endevina de forma clara el projecte vital i devocional de la sobirana, compartit per la comunitat religiosa, representada per la seva abadessa, Francesca Saportella, i per algunes dones de la noblesa, que les van acompanyar en el seu propòsit.
\end{abstract}

Paraules clau: monestir; Pedralbes; reina Elisenda; sepulcre; abadessa; murals; inventaris.

\begin{abstract}
Summary: The intention of this paper is to revisit two known inventories of the Royal Monastery of Santa Maria de Pedralbes, written in 1364 at the time of the death of both Queen Elisenda of Montcada and the abbess,Francesca Saportella. Drawing together these two texts with other documents and complementary studies of the history and architecture of the siteclearly reveals that the founding and initial design of the site were the result of a previously conceived overall plan, behind which the queen's devotional life and work can be surmised. The religious community, represented by the abbess Francesca Saportella, participated in the project, as did other noblewomen who accompanied the queen and the abbess in their objective.
\end{abstract}

Keywords: monastery; Pedralbes; Queen Elisenda; tomb; abbess; mural paintings; inventories.

\footnotetext{
${ }^{1}$ Abreviatures utilitzades: ACA = Arxiu de la Corona d'Aragó; AHRMSMP = Arxiu Històric del Reial Monestir de Santa Maria de Pedralbes; ASV = Archivio Segreto Vaticano; UAB = Universitat Autònoma de Barcelona; UB = Universitat de Barcelona.
} 
1. Un nou monestir de clarisses a Petras Albas.- 2. Elisenda de Montcada, promotora del monestir.- 3. El palau i la cort de Pedralbes en vida de la reina.- 4. La construcció del monestir, una idea compartida?.- 5. Conclusions.- 6. Bibliografia citada

\section{UN NOU MONESTIR DE CLARISSES A PETRAS ALBAS}

El Monestir de Pedralbes és una joia de l'art gòtic català. Començar un article amb aquesta afirmació sembla una obvietat i no obstant, no per massa repetit, deixa de ser una certesa. La sensació que la seva visió produeix encara avui al visitant és la d'un conjunt arquitectònic harmònic i d'una sòbria bellesa que va fer exclamar a l'arquitecte francès Le Corbusier quan el va visitar l'any 1928: El Monestir de Pedralbes: quina simplicitat més moderna. És el millor que he vist a la vostra terra.

Encara que al llarg del temps transcorregut des de la fundació del monestir el 1327 fins al present, el conjunt ha estat objecte d'intervencions i remodelacions que han afegit nous volums al conjunt o han modificat algunes de les seves parts, no obstant això, ni la planta ni la traça del projecte arquitectònic original s'han vist desvirtuat i es poden resseguir encara avui perfectament. La preservació d'aquest esquema primigeni ens permet reconstruir amb força precisió el procés constructiu que va experimentar el cenobi en les seves etapes inicials i ajuda a suplir la mancança de documentació precisa de l'obra que, sens dubte, la construcció d'un complex tan gran i de les característiques del de Pedralbes havia d'haver generat. Una documentació que, possiblement, va ser enregistrada en llibres i manuals diversos que es portarien a terme des de la mateixa cancelleria de la reina Elisenda (1292-1364), primer, encara resident al Palau Reial Major de Barcelona com a reina consort del rei Jaume II (1267-1327), i abans de la inauguració del monestir, i, posteriorment, com a reina-vídua, un cop instal·lada al seu nou palau de Pedralbes a redós del monestir ja consagrat. Al seu costat s'anava consolidant una inicial comunitat de religioses clarisses que aniria augmentant en bona part, gràcies a les rendes que li proporcionava la mateixa reina. Cap d'aquesta documentació "de fàbrica" ha estat localitzada entre el nombrós fons arxivístic que la mateixa comunitat de clarisses, en tant que hereves de tots els béns de la reina, conserven al seu propi monestir ${ }^{2}$. Tampoc s'ha trobat cap informació entre els registres

\footnotetext{
2 AHRMSMP. La comunitat conserva un ric arxiu patrimonial que és fruit de la llarga i ininterrompuda historia de la religioses clarisses en aquest monestir. Tot i que al llarg d'època moderna l'arxiu ja va ser objecte de diverses classificacions i de l'edició de compendis dels documents més importants, hem de donar a sor Eulàlia el mèrit d'haver estat ella la primera per-
} 
de cancelleria pertanyents al període del regnat del rei Jaume II, que contenen apartats específics de les diferents esposes del rei, la reina Blanca d'Anjou, la reina Maria de Lusignan i la mateixa Elisenda ${ }^{3}$.

Malgrat aquesta mancança, si que s'han conservat els documents fundacionals més rellevants, tals com la compra de la propietat del mas Pedralbes a Bernat de Sarrià i el del domini directe del mateix que es trobava en mans d'Elisenda, vídua d'Arnau de Pedralbes i el seu fill Bernat ${ }^{4}$. Igualment s'ha preservat la butlla del papa Joan XXII de l'1 de febrer de l'any 1325, en el que atorga la facultat a la reina de fundar el monestir i dotar-lo dels seus propis béns per sostenir a la comunitat que allà s'hi hauria d'aplegar ${ }^{5}$, i el document de reconeixement i sanció del lloc escollit per part del ministre provincial fra Ramon Bancal, que anava acompanyat d'altres frares menors: fra Arnau de Canelles, fra Berenguer Folcini i fra Pere de Comabella ${ }^{6}$. En aquest mateix document es feia menció que el mateix provincial va nomenar com a directors de l'obra Ferrer Peyró i Domènec Granyena, capellà i tresorer respectivament de la mateixa reina.

Arribats a aquest punt, res de nou aportem al que ja és conegut i ha estat tractat en diversos assajos sobre la construcció i l'autoria del mones$\operatorname{tir}^{7}$ i no obstant, volem tornar sobre aquest tema des d'una altra perspectiva. En línia amb el que Therese Martin plantejava en la introducció del darrer volum d'estudis que ha coordinat, després que avui disposem ja d'un bon nombre d'estudis que mostren el paper important jugat per les dones com a

sona en portar a terme una classificació dels fons de l'arxiu seguint una metodologia científica. Aquesta classificació seria la base de la seva monografia sobre el monestir que va titular: Fulles Històriques. Avui, en conveni entre la mateixa comunitat, la Direcció de Patrimoni i Arxius de la Generalitat de Catalunya i l'Ajuntament de Barcelona, a través del Reial Monestir de Santa Maria de Pedralbes, s'està ultimant un projecte de nova catalogació i digitalització d'aquest fons seguint les normatives internacionals. No obstant, aquesta nova classificació respectarà la ubicació física i la classificació feta per sor E. Anzizu com un testimoni del moment històric en que es va realitzar.

3 J.E. Martínez, Jaime II de Aragón. Su vida familiar, p. 11.

${ }^{4}$ AHRMSMP, Llibre de Privilegis Reials, P/17, ff. 247-253.

5 AHRMSMP, Perg. 113; Llibre de Privilegis (s. XIV), ff. 25v-26; Llibre de Privilegis Apostòlics, P/16, ff. 81-84.

${ }^{6}$ AHRMSMP, Perg. 169M; Llibre de Privilegis (s. XIV), ff. 25v-26; Llibre de Privilegis Apostòlics, P/16, ff. 77-85.

${ }^{7}$ El paper de directors i d'auditors de comptes, i no d'autors del projecte, dels dos personatges esmentats, ja havia estat posat de manifest per Sanpere i Miquel en la seva obra La pintura mig-eval catalana, p. 59. Posteriorment, Josep Rius Serra, també va insistir en la mateixa idea en un article sobre l'obra de Ferrer Peyró. J. Rius, Ferrer Peyron y el monasterio de Pedralbes, pp. 75-77. Darrerament, tracten la qüestió algunes tesis doctorals presentades sobre el monestir de Pedralbes: A. Nualart, Les pintures murals negres; C. Sanjust, L'obra del Reial Monestir, i F. Bazzochi, Las vidieras góticas mediterráneas, així com F. Bazzochi Las vidrieras góticas, pp. 24-37. Malgrat tot no s'ha pogut avançar en aquest aspecte. 
promotores i receptores de l'obra d'art, el que sembla que cal ara plantejarse són nous temes de debat ${ }^{8}$. Ana Maria S.A. Rodrigues, en un interessant estudi dins la mateixa publicació, abunda en la idea i planteja alguns dels possibles interrogants a tractar, com ara, si el patronatge artístic de les reines diferia del de les abadesses i del de les altres dones de l'aristocràcia, el que porta a l'autora a analitzar les actuacions que en aquest sentit van dur a terme quatre reines dels regne hispànics al llarg del segle XIV, entre les quals hi hauria Elisenda de Montcada, a les que ens referirem en el present estudi ${ }^{9}$.

Creiem que, partint del testimoni excepcional que suposa el monestir de Pedralbes, és possible fer una relectura de determinats testimonis documentals, com per exemple, els inventaris redactats a la mort de la reina i de l'abadessa Francesca Saportella, l'any 1364. La informació que aporten, juntament amb d'altres documents que s'analitzen a ulls del coneixement de què avui es disposa sobre l'evolució historicoarquitectònica de l'indret, permet reconèixer el projecte inicial global al que responia el monestir, així com el paper promotor de la reina, el de la comunitat de religioses, amb l'abadessa Francesca Saportella al capdavant, i el d'algunes dones de la noblesa religioses o no, que les van acompanyar en el seu desenvolupament.

\section{Elisenda de MONTCADA, PROMOTORA DEL MONESTIR}

Tot i el suport que Elisenda va rebre del rei per dur endavant el seu projecte fundacional, no sembla haver-hi cap dubte que el mèrit de la ideació, gestació i primers passos perquè es pogués fundar un nou cenobi de religioses clarisses a l'entorn de Barcelona, li correspon a ella.

La primera evidència de la determinació de la reina en aquest sentit, el trobem en l'elecció de l'espai. Tant sor Eulàlia Anzizu com, posteriorment, l' historiador i biògraf del rei Jaume II i la seva família, Martínez Ferrando, en els seus estudis del monestir recollien el fet documentat que el rei havia fet una primera donació a la seva esposa d'uns terrenys de caça que la corona posseïa al terme de Valldaura perquè hi pogués construir el nou monestir. Igualment, feien esment del fet que la reina no va acceptar aquest oferiment, tal com evidencia el document d'anul·lació d'aquell acte ${ }^{10}$, i sí en canvi la

8 Th. Martin, Exceptions and Assumptions, pp. 1-36.

9 A.M. S.A. Rodrigues, The treasures and foundations, p. 905.

${ }^{10}$ E. Anzizu, Fulles Historiques, pp. 12-13; J. Martínez Ferrando, Jaime II de Aragón y su vida familiar, p. 18; A. Castellano-Tresserra, Pedralbes a l'edat mitjana, pp. 36-37. 
suma necessària per adquirir les possessions del mas Pedralbes que el mateix dia li va fer el monarca ${ }^{11}$.

Certament Pedralbes oferia un espai més obert i menys ombrívol que Valldaura i tal vegada més ben comunicat amb la cort barcelonina. Als peus de la muntanya de Sant Pere Màrtir, es presentava com una zona amb pendent suau amb diferents terrasses, solcada per rierols, mines i pous d'aigua que convertien la zona en un indret idoni pel conreu. Així havia estat des d'època romana com ho testimonien les restes d'una antiga vil-la romana que s'han trobat a la zona ${ }^{12}$. No era estrany doncs, que quan la reina es va fixar en el lloc aquest ja estigués ocupat per un mas en ple rendiment.

Semblaria que si la reina havia pogut gaudir de la llibertat per rebutjar l'oferta del rei, la tindria també per decidir sobre el nou indret i, per tant, podem suposar que ja fos per ella mateixa o per indicació del seu entorn, el fet d'escollir el mas Pedralbes no va ser per atzar sinó una decisió ben estudiada. Podria confirmar aquesta idea el fet mateix que quan el ministre provincial fra Ramon Bancal va anar a reconèixer el lloc l'1 de juliol del 1326, va escollir com a directors de la nova obra els assessors més directes de la reina, el seu capellà Ferrer Peyró i el seu tresorer, Domènec Granyena. No hem de passar per alt el fet que, quan l'esmentat ministre va acudir al lloc, ja havia estat col·locada la primera pedra a la capçalera de l'església, el 26 de març d'aquell mateix any, davant la presència dels monarques; al provincial doncs, li va correspondre només la tasca de sancionar el lloc escollit, i si bé el document manifesta que va ser el provincial qui va delimitar l'espai que ocuparia la clausura, seguint la traça $i$ el costum de les monges i el seu propi criteri, és evident que les línies generals ja estaven definides sobre el terreny, atès que la pedra fundacional ja marcava el lloc que havia d'ocupar la capçalera de l'església ${ }^{13}$. Un altra document, en aquest cas emès des de la cúria papal, confirmava que la reina havia escollit a Ferrer Peyró perquè exercís com a procurador general, benefactor, ordinador $i$ gestor dels edificis, rèdits $i$ ordinacions del monestir ${ }^{14}$. És de pensar que li correspondria a aquest, o al tresorer, Domènec Granyena, l'enregistrament de

${ }^{11}$ ACA, Registres de Cancelleria, $\mathrm{n}^{\circ}$ 227, ff. 272v-273r. Aquest mateix document també va ser estudiat per C. Rubert i publicat a 1' "Archivo Ibero-Americano", any XIII, (juliol-desembre 1926), pp. 375-387.

12 A. Castellano-Tresserra, Pedralbes a l'edat mitjana, pp. 35-36.

13 AHRMSMP, Perg. 113 i 169M. Llibre de Privilegis, P/15, ff.25v-26r. Llibre de Privilegis Apostòlics, P/16, ff. 77-85.

14 Aquesta informació ja l'hem presentada en treballs anteriors i ha estat recollida de l'estudi de J. Rius Serra, Ferrer Peyrón y el monasterio, qui havia consultat aquest document a l'Arxiu Vaticà, dins el Reg. Avinonensium 88, f. 446, n. DCXXV i al Reg. Vaticanum 176, f. 247, n. 623 . 
totes les despeses que l'edificació d'un complex d'aquella envergadura, sens dubte havia de generar, anotacions que, com hem dit, fins el present no ha estat possible de localitzar. Abundaria en aquest sentit el fet que la relació de Ferrer Peyró amb el monestir es va mantenir llarg temps ja que ens consta que encara el 1347, les seves funcions al monestir devien ser prou estretes com perquè des de la cúria papal, el 15 de febrer d'aquell any, se li concedís un permís per poder pernoctar al monestir malgrat la clausura ${ }^{15}$. No ens ha de passar per alt el fet que el primer manual notarial que constava al monestir al moment que sor Eulàlia va fer el seu inventari, corresponia al notari Guillem Turell i abraçava els anys $1342-1348^{16}$. Aquesta constatació ens fa pensar encara més que, almenys fins aquells anys, tota la documentació que l'obra devia haver anat generant, hauria estat sufragada i controlada per la Cúria de la reina, segurament amb el seu total coneixement ${ }^{17}$.

Des del 26 de març en què s'havia col-locat la primera pedra del nou cenobi, les obres devien haver avançat prou ràpidament com per poder haver-se edificat ja unes primeres estances per les religioses. Contràriament, tot i que la mala salut del rei podia haver fet preveure un desenllaç proper, no és tant clar que les obres del futur palau de la reina, al costat del monestir, s'haguessin iniciat també en aquell primer moment, malgrat estiguessin en el pensament de la reina. Si ens fixem en el resultat final de l'obra un cop ja acabada, apreciem com les mesures de l'església van ser pensades per tal que la volta que havia de cobrir la nau, fos de set trams més la capçalera que, a la seva vegada, dibuixava set costats que s'il-luminarien amb els set vitralls corresponents que encara avui conserven la traceria, els ploms i bona part de les vidrieres gòtiques. El fet contestable és que

15 ASV, Reg. Avinonensium 88, f. 446.

${ }^{16}$ Tot i la pèrdua del Manual de Guillem Turell (1342-1348) que contenia en el seu f. 70v. el contracte de les pintures de la capella de Sant Miquel al pintor Ferrer Bassa fet el 1346; la fotografia i transcripció d'aquest document es pot veure en el llibre de M. Trens, Ferrer Bassa $i$ les pintures de Pedralbes, pp. 172-173. Igualment a l'arxiu del monestir encara es conserva un full solt amb un altra contracte fet uns anys abans, el 1343, al mateix pintor per aquesta obra. AHRMSMP, Pintures (1342-1348), Lligall 184.

17 L'actual arxivera de la comunitat, sor Immaculada Parera, ens va mostrar una nota que es conserva a l'arxiu nou del monestir -que recull la documentació del darrer segle XX i la contemporània- redactada per una germana arxivera anterior, sor Maria del Sagrat Cor Grané, on deixava constància que segons li havia comunicat personalment mossèn Trens, segurament aquest manual es trobava a la biblioteca de casa seva, entre els documents que estudiava per a la seva tesi doctoral sobre les pintures de la capella de Sant Miquel, quan en els primers moments de la revolta del 1936, aquesta va ser saquejada i cremada. Sigui cert el fet o no, ara com ara el manual no s'ha pogut retrobar tot i les diferents gestions efectuades per la comunitat amb diverses institucions on presumiblement podia haver anat a parar durant $i$ després de la guerra, a les que s'ha d'afegir les nostres pròpies recerques que han proporcionar el mateix resultat infructuós. Com hem dit, tampoc hem trobat fins el present, documentació dels anys anteriors en referència a les obres que s'estaven efectuant. 
una nau d'aquestes mesures encaixa a la perfecció a la terrassa mitjana de les tres sobre les que s'assenta el monestir, deixant encara un espai sobrer abans del desnivell cap a la tercera terrassa, en direcció sud, on es podia aixecar una de les ales de tancament del claustre i les estances que s'hi determinessin, tot i que, en aquell moment, una part sembla que ja estava ocupada per una edificació anterior. Aquestes àmplies dimensions permetrien la construcció d'un conjunt monàstic on l'església servia de partió entre el mon interior i l'exterior. Mentre el "pati" de fora , tal com l'anomenen els documents, es constituïa com el centre al voltant del qual es van anar aixecant les edificacions del personal de servei extern, inclosos els frares i capellans, a l'altra cantó de l'església, dins la clausura, el claustre exerciria una funció semblant, com a epicentre de la vida monàstica, en tant que distribuïdor de les diferents estances i com a espai de meditació i recolliment personal de les religioses.

Les diferents terrasses del terreny a més, oferien encara un altra avantatge en tant que permetien una fàcil construcció sobre la terrassa superior, d'un primer cos als peus de la nau de l'església, amb unes mesures equivalents a dos trams de volta de la nau, al que s'hi va afegir un tercer que s'avançava sobre la terrassa immediata inferior en forma de voladís, permetent al seu dessota disposar d'un espai entre el mur natural del terreny i un altre edificat de tancament que podia separar la primera clausura de la resta de la nau en obres. Seria l'espai que avui coneixem com a "cor de baix". Amb l'espai superior construït, l'actual "cor de dalt", i un cos annex que podria coincidir amb l'anomenada "sala de l'àngel", la petita comunitat originaria de dotze monges, catorze novícies i dues llegues podrien haver disposat ben ràpidament, $\mathrm{amb}$ només un any, d'uns primers espais per recollir-se, mentre les obres continuaven a tota la terrassa inferior, on hi tindria l' accés un possible primer lloc de culte que coincidiria amb el "cor de baix" al que tindrien accés els fidels en tant duraven les obres de l'església i que tal vegada, podria coincidir amb l'espai consagrat i inaugurat pels reis el 3 de maig del $1327^{18}$. L'elecció del lloc de Pedralbes, doncs, no sembla gens casual sinó molt ben estudiada i encaixava a la perfecció, o s'hi va fer encaixar, amb el projecte devocional que s'hi volia plasmar, darrera del qual i endevinem la presència de la reina.

18 A. Nualart, en la seva tesi doctoral, Les pintures murals negres, apuntava que "amb l'església en construcció no seria desencertat imaginar que la petita nau del cor de baix hagués fet funcions provisionals de capella", Les pintures murals negres, p. 39. També en la seva tesi doctoral, C. Sanjust fa esment de la possibilitat que l'església ja estigués en ús abans de ser enllestida del tot. C. Sanjust, L'obra del Reial Monestir. 


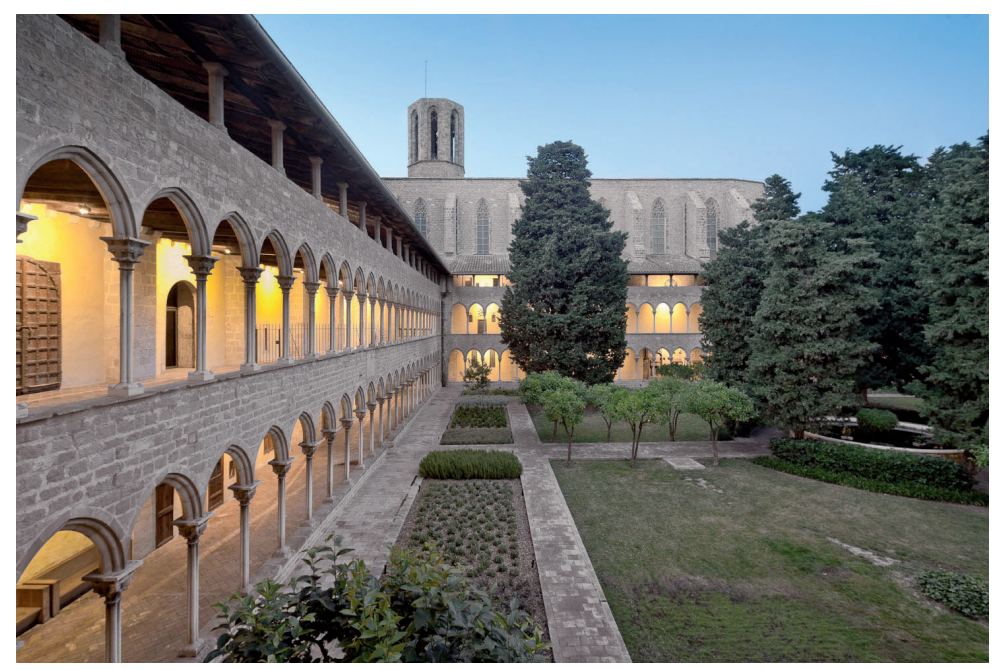

Fig. 1. Detall de l'ala nord del "dormidor" des de l'emplaçament de l'anomenada "sala de la reina". Des d'aquí, és possible observar al fons el monument funerari de la sobirana. Reial Monestir de Santa Maria de Pedralbes, Pere Vivas, 2013.

\section{El PALAU I LA CORT DE PEDRALBES EN VIDA DE LA REINA}

Molt poc després de l'acta d'inauguració del monestir, el rei Jaume II moria al palau reial de Barcelona, era el 2 de novembre del mateix any $1327^{19}$. Un seguit de missives enviades a començament de l'any següent mostren que un cop acabades les exèquies reials, la reina-vídua es va traslladar a viure al palau de Pedralbes, abans, fins i tot, que fos coronat el nou rei, sense que això signifiqués un allunyament de la reina de certs assumptes de la cort. Concretament, una carta enviada per la mateixa Elisenda al nou sobirà, el rei Alfons, el 25 de febrer de l'any 1328, testimonia que ja residia al nou palau. A la missiva la reina s'interessava per la salut del nou sobirà i per les cerimònies de la seva propera coronación ${ }^{20}$.

Que el conjunt monàstic encara estava en fase de construcció després de la seva inauguració, s'intueix en l'encapçalament de la primera ordinació que va redactar la reina el 7 de novembre de l'any 1327, només quatre dies més tard del traspàs del rei:

19 Tot i els anys transcorreguts des de la seva publicació, l'obra de l'historiador Martínez Ferrando segueix sent una font inestimable per a conèixer la vida i la personalitat del rei Jaume II i la de la seva família. J.E. Martínez Ferrando, Jaime II de Aragón. Su vida familiar .

20 J-F. Cabestany, Aportació a la biografia de la reina Elisenda. 
De grat e de certa sciència offerim, atorgam, donam e liuram a nostre senyor Déus, e a la benauyrada sancta mare sua, e a vós, na Subirana, abadessa del dit monestir, reebén per nom d'aquell monestir, e al covent d'aquell, presens e esdevenidores, e per tots temps, lo damon dit monestir e l'esgleya d'aquell, e totes les cases axí edificades com edificadores en lo dit monestir de Santa Maria, $\mathrm{e} a b$ orts, $\mathrm{e} a b$ totes tenències e pertinències e drets sa enrere pertanyens al dit mas de Pedralbes, lo qual nós avem comprat a ops del monestir damon dit ${ }^{21}$.

Es pot al·legar que l'esment a totes les cases axí edificades com edificadores, no és més que una frase estereotipada de l'estil de les emprades habitualment en les escriptures de compra-venda de finques, per tal d'assegurar que quedessin inclosos els possibles canvis o ampliacions que es poguessin fer en el futur. Es podria entendre així si no sabéssim per d'altres fonts que el conjunt s'anava configurant paulatinament $i$, per tant, la reina preveia que quedaven cases per construir. És ben possible que quan Elisenda es va instal·lar al seu nou palau tampoc aquest estigués enllestit i que es conclogués estant ja ella vivint al lloc. Tampoc en aquest cas disposem de dades i haurem d'esperar als moments posteriors a la seva mort per fer-nos una idea de com era aquest palau al final de la vida de la reina.

Una primera incògnita es planteja en voler ubicar físicament aquest palau, ja que, tal com han recollit tots aquells historiadors que han estudiat el monestir i la figura de la reina, aquesta va manar en el seu testament que el seu palatium fos enderrocat després del seu traspàs, conservant-se únicament, la sala principal d'aquell palau ${ }^{22}$. Si bé, alguns historiadors han proposat que les estances reials es podien haver aixecat al cantó sud del monestir, on ara es troba la sala capitular, sembla més versemblant la hipòtesi que el situa a l'ala nord, al costat del Dormidor de les monges,i que justament la sala principal a la que la reina fa al·lusió perquè es mantingui, pogués ser efectivament, la que es coneix com a "sala de la reina", a la cantonada nord-oest. Aquesta proposta

${ }^{21}$ AHRMSMP, Perg. 999; Llibre de Privilegis, P/15, ff. 27-32v; Lligall Fundacions, n. 124; Llibre de la Regla, R/25. La transcripció que aquí oferim correspon al document original en llengua catalana que es recull a l'esmentat Llibre de Privilegis, P/15.

22 "Item, volumus et mandamus quod post obitum nostrum, totum hospitium familis nostra et palatium eiusdem familia, diruatur usque ad palatium nostrum in quo comedimus, usque ad januam ipsius, quiae est coram januam dicti palatii, et postea ipsa janua claudatur et paredatur, et etiam janua portualis maioris familia nostrae", Llibre de Privilegis i Donacions Reials, P/17, ff. 219-236. El document original va ser redactat sobre pergamí. Perg. 94: Testament de la reina Elisenda de Montcada. Els documents originals que es conserven a l'arxiu del monestir de Pedralbes sobre la reina, fonamentalment les diverses ordinacions, el testament i els inventaris fets posteriorment a la seva mort, van ser transcrits en la nostra tesi doctoral a la qual remetem (A. Castellano, Origen $i$ formació, pp. 794-838); no havien estat objecte de publicació ni revisió posterior fins a la present anàlisi. 
disposa al seu favor que es trobaria als peus de l'antic camí que des de Sarrià anava cap a Esplugues pel coll de Finestrelles, un camí amb una traça molt antiga que es remunta a època romana.

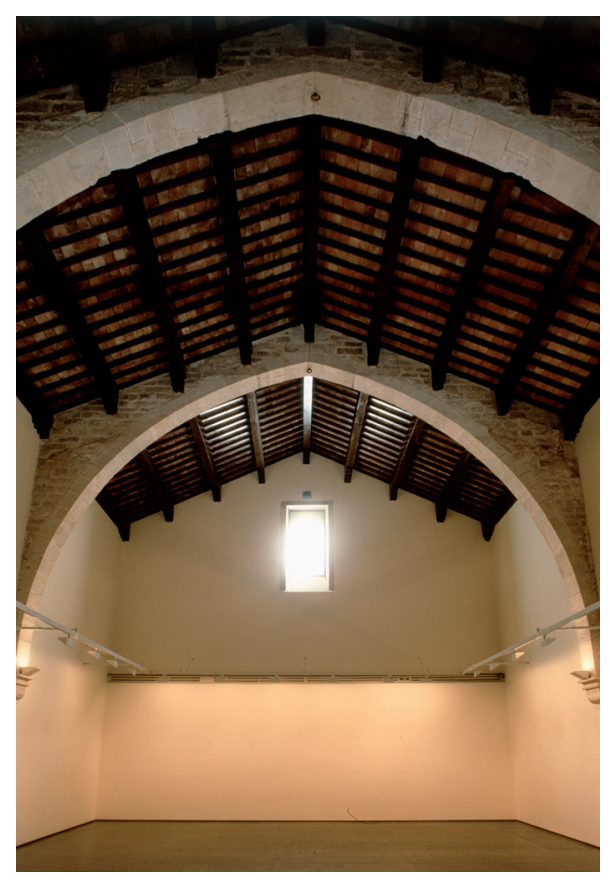

Fig. 2. Imatge de l'anomenada "sala de la reina" després de la remodelació que en va retornar el seu aspecte original, després d'haver servit durant anys de noviciat. Reial Monestir de Santa Maria de Pedralbes, 2003.

Igualment, un document reforçaria aquest possible emplaçament, es tracta del permís que el cardenal Talayrandus, protector de l'orde, va emetre a favor de la reina el 18 de maig de 1363, per correspondre als mèrits que la sobirana havia fet al llarg de la seva vida pel monestir. El permís contemplava poder obrir una porta de comunicació entre el palau i la clausura de les monges, facilitant d'aquesta manera, que algunes religioses poguessin entrar a la cambra de la sobirana sempre que ella ho desitges i amb la màxima discreció $^{23}$. Del document semblaria desprendre's que només una paret separaria

23 AHRMSMP, Perg. 169. E. Anzizu, pp. 65-66. La informació que aquí detallem és prou coneguda i la qüestió sobre la ubicació del palau ha estat objecte de debat recorrent entre els 
les estances de la reina de les de les religioses, l'anomenada "sala de la reina" compleix aquest requisit al costat del dormidor de les religioses.

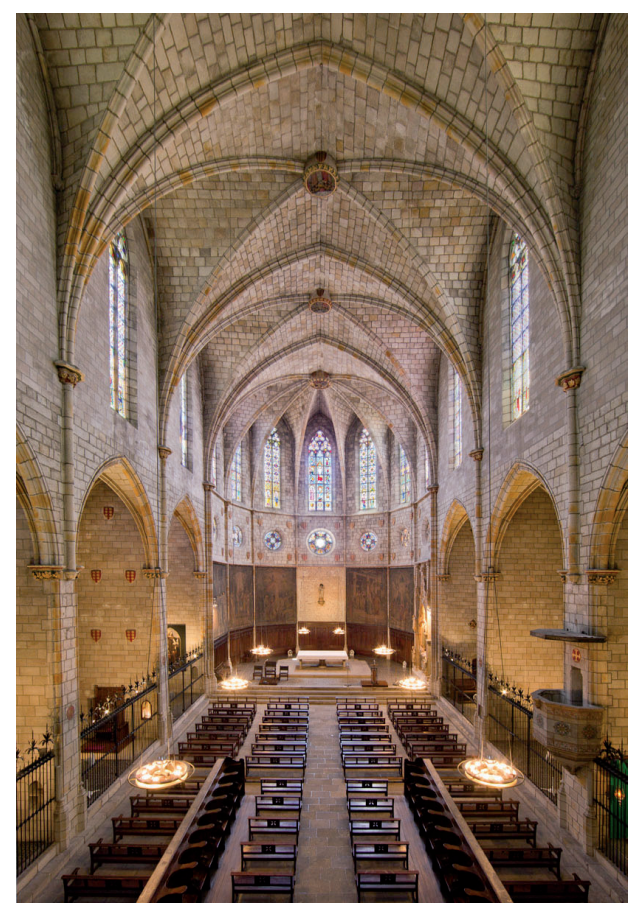

Fig. 3. Vista de la volta de l'església de Santa Maria de Pedralbes des del cor de les monges, amb les claus de volta que representen els Set Goigs de la Verge. Reial Monestir de Santa Maria de Pedralbes, Pere Vivas, 2013.

Quan el 1977, l'actual comunitat de clarisses va signar un conveni amb l'Ajuntament de la ciutat de Barcelona en el que cedia el vell cenobi com a recinte museístic i cultural per la ciutat a canvi de la construcció d'un nou convent en els terrenys de l'anomenat Hort Gran, es van iniciar unes excavacions per tal d'intentar trobar les restes del palau. Un cop es va veure que resultaven infructuoses les recerques en aquell punt, es van traslladar a la zona del noviciat, construït al segle XVII, que ocupava l'actual "sala de la reina", i que van donar com a resultat un seguit de troballes que es van interpretar

historiadors del monestir que, majoritàriament s'inclinen per ubicar-lo en l'anomenada "sala de la reina". 
com a pertanyents al palau ${ }^{24}$. De ser certa aquesta hipòtesi, l'extens inventari que l'abadessa sor Sobirana d'Olzet va iniciar un cop acabades les exèquies de la reina que van durar tres dies, l'hauríem d'interpretar a partir d'aquest emplaçament dins el conjunt del monestir. El document no només permet una reconstrucció física de les diferents estances que conformaven aquest palau, sinó a més, a través de l'enumeració dels diferents objectes que s'hi van trobar, esbossar un perfil de la personalitat de la reina que pot ajudar a completar la imatge que de forma calculada ella volia que subsistís de si mateixa, un cop desaparegut ja el seu palau i distribuiits i venuts tots els seus béns. És en aquest sentit que adquireix molt valor aquest inventari que descriu tot allò que envoltava a la reina ${ }^{25}$.

La primera persona que va analitzar aquest document, que com altres importants de la reina es custodia al mateix arxiu de la comunitat, va ser sor Eulàlia Anzizu en la seva monografia sobre el monestir de Pedralbes ${ }^{26}$. En aquesta obra l'autora transcrivia part de l'inventari però n'obviava diversos paràgrafs el que li donava peu a afirmar que les estances de la reina es distingien per una marcada austeritat. La lectura completa del document permet matisar aquesta primera imatge.

\footnotetext{
${ }^{24}$ Aquestes exploracions van ser dutes a terme pels Serveis Tècnics del Museu d'Art de Catalunya (avui Museu Nacional d'Art de Catalunya) en col-laboració amb un equip d'arqueòlegs del Museu d'Història de la Ciutat de Barcelona (avui Museu d'Història de Barcelona). Els resultats van ser publicats al diari de Barcelona, La Vanguardia Española, per M. Assumpta Escudero, el dia 7 d'abril del 1974. La mateixa autora en torna a fer esment en la guia del monestir, publicada l'any 1988, pp. 19 i 50. Igualment disposem d'un diari de les excavacions, manuscrit, redactat segurament per la mateixa autora, en el que es detalla el procés seguit $i$ les troballes diàries que van portar a identificar, al seu parer, el palau de la reina, en la zona del noviciat.

${ }_{25}$ AHRMSMP, Lligall. Inventaris, Inventari pres la Ill. Sra. Abaddessa del Real Monastir, n. 137. Com ja s'ha dit, vam tractar per primera vegada aquest inventari en relació a la personalitat de la reina Elisenda de Montcada a la nostra tesi doctoral A. Castellano, Origen i formació, pp. 589-603. Un coneixement més a fons de la personalitat de la reina a través de diversos estudis que s'han anat fent en els darrers anys, fa que vulguem tornar a analitzar aquest inventari. Remetem a aquest primer estudi on es troba la transcripció íntegra del document.

${ }^{26}$ Sor Eulàlia Anzizu és una figura cabdal pel coneixement de la història del cenobi i també per la recuperació del propi monestir que a final segle XIX, presentava una certa decadència física i econòmica. La personalitat erudita de sor Eulàlia, educada dins els cercles de la Renaixença sota la tutela del seu oncle, el comte Eusebi Güell, i el considerable dot que va aportar al monestir en ingressar, possibilità que la comunitat prengués consciència de l'important patrimoni que custodiava i s'iniciés una fase de recuperació que, amb ajut de les institucions públiques, ha permès que el monestir de Pedralbes pugui ser admirat avui amb tota la seva magnificència original. A sor Eulàlia li correspon el mèrit d'haver fet una classificació de tota la documentació que es conservava al monestir que va constituir la base de la seva obra Fulles Històriques que constitueix la primera monografia històrica del monestir i que segueix sent una referència important encara avui. Aquesta monografia va sorgir després d'haver dut a terme unes primers notes cronològiques que encara es conserven a l'arxiu: "Notes cronològiques relatives al monestir" dins Index general de l'Arxiu del Real Monestir de Santa Maria de Pedralbes, 1899 (notes manuscrites).
} 


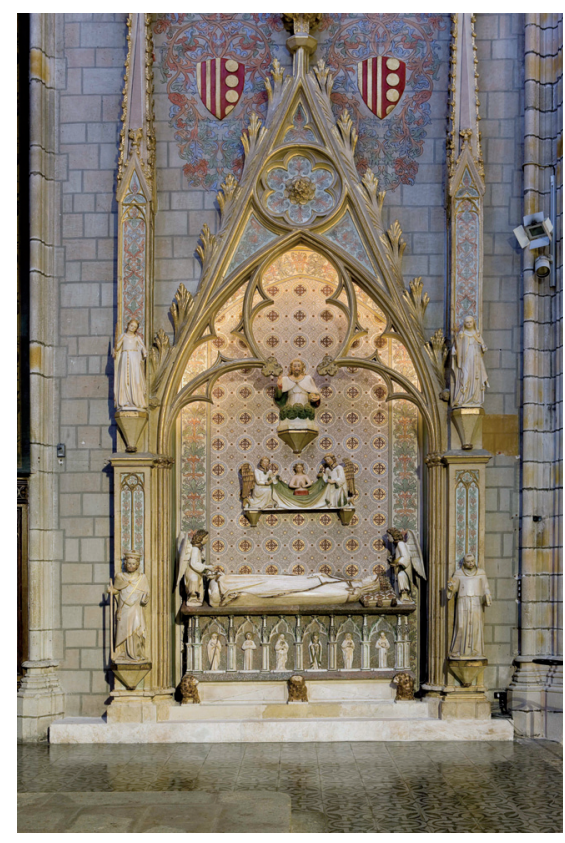

Fig. 4. Monument funerari de la reina Elisenda de Montcada emplaçat al presbiteri de l'església. Paral·lelament, pel cantó del claustre, la figura de la reina apareix abillada com a penitent. Reial Monestir de Santa Maria de Pedralbes, Jordi Puig, 2008.

El registre es va iniciar el divendres 26 de juliol del 1364, i es va donar per acabat el dimarts 10 de setembre del mateix any. L'encarregada va ser l'abadessa sor Sibil·la de Queixans, que ho va fer en nom de la comunitat del monestir de Pedralbes que havia estat designada per la reina com hereva universal de la totalitat dels seus béns particulars, a excepció d'allò que deixava expressament a d'altres familiars o persones acostades.

La reina havia disposat com a marmessors testamentaris diverses persones, però aquestes van delegar la missió de dur a terme el registre a Arnau de Carbessí, rector de l'església de Cubells, a la diòcesi d'Urgell, que havia estat igualment, escollit per Elisenda com a marmessor.

La relació de béns i estances es va començar justament, per la cambra major del palau, que es podria interpretar com un indici més que era aquesta l'estança més propera a les dependencies monàstiques ${ }^{27}$. Per la descripció

27 "Primum itaque invenimus in hereditate et bonis qua fuerunt dicta inclita domina regina in camera videlicet maiori palatii eiusdem domina regina res sequentes" AHRMSMP, Lligall. Inven- 
dels objectes que s'hi esmenten sembla que es tracta de la sala on la reina hi guardava les seves peces més valuoses, i on devia rebre a les personalitats que acudien a visitar-la. Desconeixem el grau d'activitat pública d'Elisenda, però ens consta que, efectivament, rebia a diverses personalitats ja que en les seves ordinacions del 1345 contemplava el fet que les despeses que ocasionaven les visites de persones que acudien a la seva cort, anessin a càrrec seu ${ }^{28}$. Es parla en aquest cas de persones religioses, però cal també pensar que n'hi acudirien moltes de laiques per qüestions relacionades amb les nombroses propietats que la reina conservava, o per la relació que seguia mantenint amb la cort, com seria el cas de la visita rebuda del cavaller Jaume Marc, al qual farem esment més endavant.

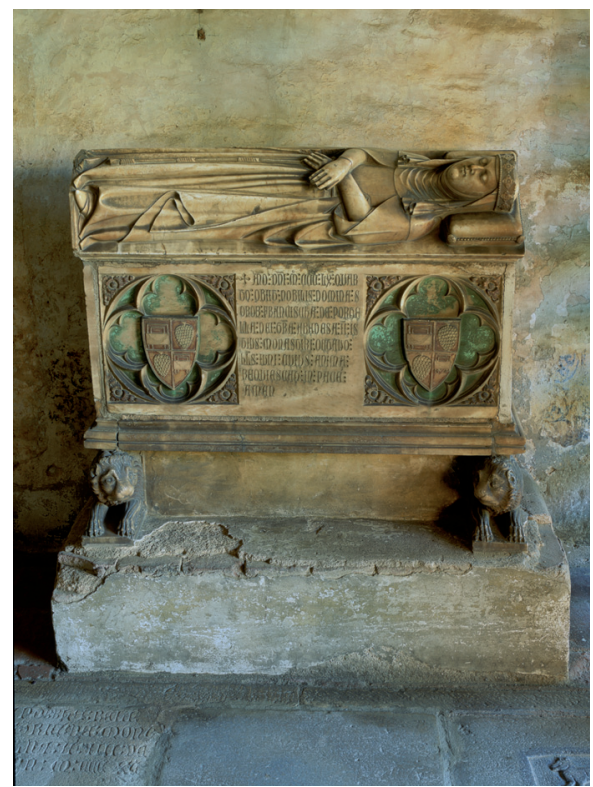

Fig. 5. Al costat de la reina, al cantó del claustre, s'hi troba la tomba de la seva neboda, l'abadessa Francesca Saportella, morta com ella l'any 1364.

Reial Monestir de Santa Maria de Pedralbes, Pere Vivas, 2001.

taris, Inventari pres la Ill. Sra.Abaddessa del Real Monastir, n. 137. Trasllat del testament de la reina Elisenda de Montcada, fet pel notari de Barcelona Josep Francesc Mas i Vidal l'any 1797, del document original redactat el 10 de setembre de 1364, davant del també notari de Barcelona Pere Borrell, sobre pergamí, ressenyat amb el número 94.

${ }^{28}$ En aquest document de l'any 1345 , la reina parlava que li corresponia a ella i no al convent, l'obligació de sufragar les necessitats dels "frares i capellans" que acudien a la seva cort AHRMSMP, Institució (lligall 136). 
En aquesta cambra s'hi trobaven un seguit de cofres on es guardaven diversos objectes de valor. A l'interior del primer d'ells, folrat interiorment amb cuir vermell i ornat amb ferramentes, s'hi van observar diversos saquets que contenien part dels estalvis de la reina, en moneda de diferent tipus: sous i diners a més de florins d'or i croats de plata.

És difícil establir un càlcul exacte dels diners de la reina, ja que el que aquí es va enregistrar només era una part del que ella disposava; una altra part, ja s'havia traslladat al dormitori del monestir, on es guardava en diversos sacs dipositats dins una primera caixa petita i aquesta, al seu torn, dins d'una altra més gran de fusta de noguera. Calia afegir a aquests diners en metàl-lic, els préstecs que havia fet la reina i que manava als marmessors testamentaris que reclamessin.

En un segon cofre de color verdós, decorat amb els signes reials i els de Montcada, s'hi guardava tota la vaixella de plata i d'altres objectes del mateix metall o d'or i plata, decorats amb esmalts o amb les armes de la reina: diverses bacines que servien per a rentar-se les mans abans dels àpats, un tallador gran, una barca decorada amb quatre lleons, vint escudelles, un saler, dinou tasses d'un joc i d'altres de soltes, deu plats, vuitanta-dues "cloquearias", una "menja moras" i diversos pitxers. També s'hi va comptar una copa de plata amb un cobertor de plata i or, decorada amb esmalts ${ }^{29}$.

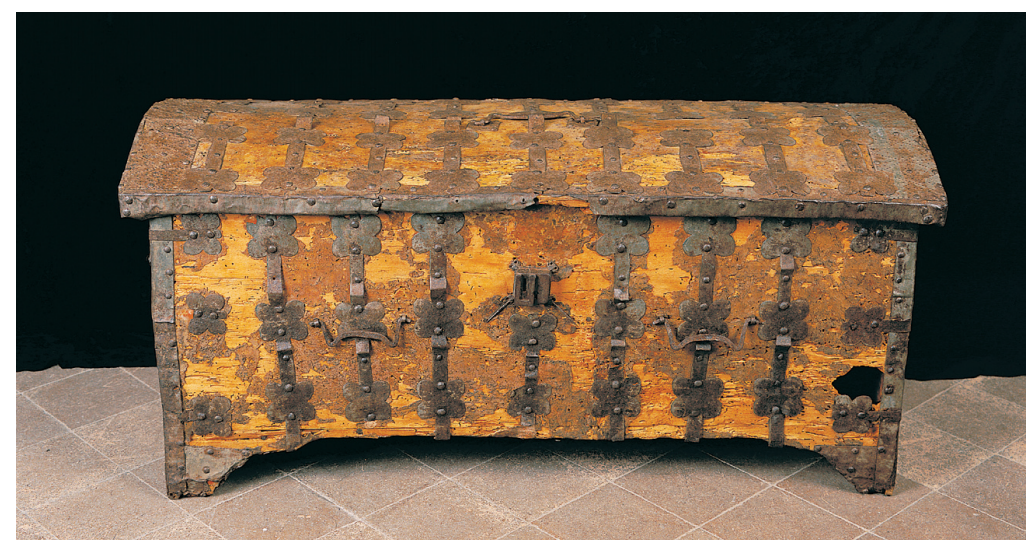

Fig. 6. Cofre conegut com a "caixa de la reina". Datat del segle XIV, és el més antic que es conserva i podia haver contingut part del tresor que la sobirana va deixar en herència al monestir. Reial Monestir de Santa Maria de Pedralbes, Jordi Puig, 2004.

\footnotetext{
${ }^{29}$ Per a la forma i la utilitat de les peces aquí descrites, és molt interessant l'estudi fet per Julia Beltrán de Heredia, sobre la terminologia i ús dels atuells ceràmics de cuina a la baixa Edat Mitjana. J. Beltrán de Heredia, Terminología, pp. 46-56. Completa aquest estudi el realitzat per Núria Nolasco sobre els atuells de fusta i metall a la mateixa època. Nolasco, Els atuells, pp. 67-70.
} 
Un tercer cofre, que presentava la mateixa decoració que el primer, contenia bona part de les joies de la reina. Sembla força clar, que es tracta de totes aquelles peces que el rei li havia anat regalant al llarg dels seus anys de matrimoni. Entre aquestes s'hi poden reconèixer perles i pedres precioses i semi-precioses que alguns documents conservats a la Cancelleria Reial descriuen com a regals que el monarca havia fet a la nova reina en motiu del seu casament, algunes d'aquestes pedres es trobaven encastades en anells i penjolls diversos ${ }^{30}$.

Altres joies es guardaven en una petita caixa de cuir negra. Potser es tractava d'aquelles que la reina tenia més a mà, i tal vegada lluïa en els seus darrers dies, ja que segons es diu, eren de poc valor. Es tractava de diverses pedres sense especificar, encastades en plata, i alguns anells d'or amb safirs i d'altres pedres semi-precioses; totes elles, segons es diu de modici valoris.

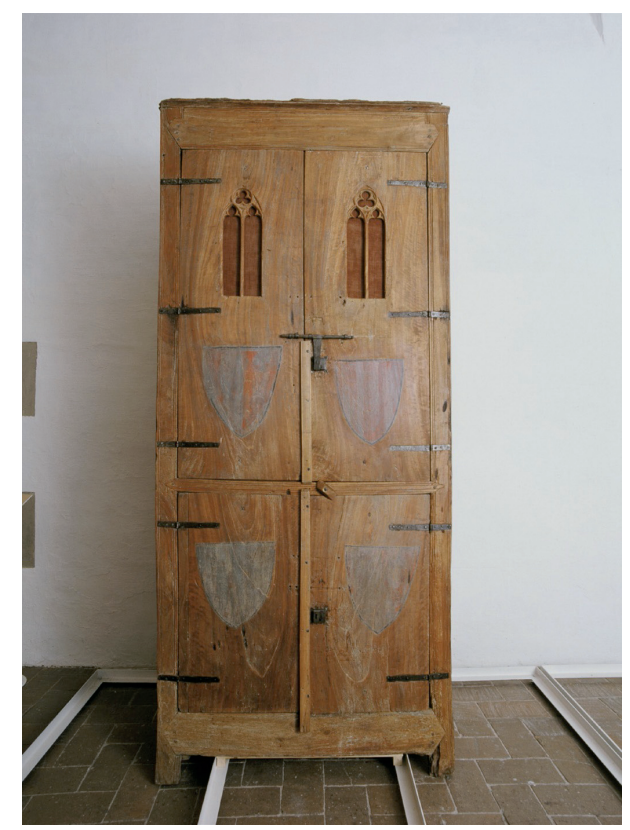

Fig. 7. Armari capella, conegut com "armari de la reina". La tradició oral l'ha considerat sempre com a pertanyent a la capella privada de la reina del palau de Pedralbes. Reial Monestir de Santa Maria de Pedralbes, Pere Vivas, 2000.

30 J.E. Martínez Ferrando, Jaime II de Aragón. Su vida familia, pp.168-206; idem, La cámara real en el reinado de Jaime II (1291-1327), pp. 168-206; F. Martorell y Trabal, Inventari dels bens de la cambra reyal, pp. 553-567; J. Rubió, R. d'Alós, F. Martorell, Inventaris inèdits de l'orde del temple, pp. 385-407. 
Malgrat la descripció acurada del que es va trobar en aquesta estança, hi manca tot esment de mobiliari com si que es fa en la resta d'habitacions. Davant d'això, cobra especial importància la descripció d'un menjar d'homenatge que la reina va oferir al seu palau, pocs anys abans de la seva mort, el 7 de desembre de 1360, a l'esmentat Jaume Marc en presència del rei Pere. L'àpat es va fer després que aquest noble fos armat cavaller pel rei Pere el Cerimoniós justament al "cor de les monges" del Monestir de Pedralbes, i tot i que no en tenim la total certesa és possible que es dugués a terme en aquesta "cambra major" que descriu l'inventari.

Seguint el relat que el mateix Jaume Marc va fer redactar en primera persona al seu llibre de la Baronia d'Aramprunyà, un cop acabada la missa en la què se l'havia armat cavaller, el rei Pere es va apropar a la reina Elisenda i, tots plegats, van sortir de l'església en direcció al palau de la mateixa reina on s'havia preparat un dinar. Segueix la narració dient:

Aixi que ans ques assigessen a la taula, lo senyor Rey volch que yo reebes lo mantel blanch ab lo senyal de la creu vermeylla; per que yo me agenoyllí als seus peus, e lo dit senyor tench los sants quatre avengelis, e feume jurar de tenir secret, e dixme alscunes paraules secretes, les quals tot cavaller es tengut de fer enves son senyor.

Apres pres un mantel blanch en que ha senyal de creu vermeylla, jo estant de genoyllons, e jure sobre la creu de tenir e servar los capitols qui son ordonats per lo senyor Rey; e de continent posam lo mantel. E apres lo dit senyor Rey e la dita senyora Reyna lavarense les mans e assigerense a la taula en la forma quis segueix:

Lo senyor Rey se assee al mig de la taula, á la part dreta, e la senyora Reyna, a la part esquerra. E apres de la dita senyora sech madona la Vezcomtessa de Cabrera, e lo senyor Rey volch que yo siges al cap de la taula, apres del. E en un altre taula sigeren totes los altres riques-dones e mullers de cavallers e mullers de ciutadans honrats.

E apres vench lo noble en Guillabert de Senteylles, Mayordom del senyor Rey, qui serví en lo Palau. Axi que y ac moltes viandes en ast e en olla, axi com paons, capons, gayllines, vadels, cabrits e bous, en ten gran quantitat que si y hages dos milia persones a totes bastaren. E con hageren menyat, passarensen lo senyor Rey e la senyora Reyna, e tota la gent, a la cambra de la senyora Reina e sigeren, axi ques raunaren de lurs bones paraules ab gran plaer e ab gran consolació.

Apres, els axi estants, vench lo dit Mayordom e feu donar vin e cumfits.

E fet aço, lo senyor Rey pres comiat de la senyora Reyna e vencsen a Barchinona ${ }^{31}$.

\footnotetext{
${ }^{31}$ F. Bofarull y Sans, El castillo y la Baronia d'Aramprunyà, pp. 96-97. La transcripció que aquí aportem es troba recollida en aquest llibre. Més recentment n'ha aparegut una nova edició, E. Cantarell, M. Comas, C. Muntaner, El llibre de la Baronia d'Eramprunyà, pp. 232-238.
} 
El relat, tot i que conegut, revesteix aquí un especial interès en la mesura que il-lumina alguns dels espais que trobem ressenyats a l'inventari. L'esdeveniment es va dur a terme en dues estances en concret; semblaria que la principal, on es va realitzar l'àpat, correspondria a la sala major, on hem vist que la reina guardava tota la vaixella de plata, justament, per ocasions com aquesta. La segona, "la cambra de la senyora reina", que, pel que direm, més endavant, podria ser l'estança on Elisenda es reunia amb les altres dames de companyia per menjar. Atès que al registre no es fa esment de mobiliari a la "cambra major" cal pensar que aquesta es preparava per ocasions com aquesta amb taules i bancs portats d'altres sales; concretament, al celler s'hi trobaven divuit taules i bancs, que semblen un nombre excessiu per les necessitats pròpies d'aquesta estança, i que potser s'hi trobaven emmagatzemades per ser traslladades, si era necessari, a algun altre punt del palau.

Segons la descripció que en fa el cavaller Jaume Marc, es van parar, almenys, dues taules, una, la principal, on seia el rei, la reina, l'homenatjat i possiblement, la dama de més categoria; res diu dels cavallers que van assistir a la cerimònia, que, possiblement també, van seure en aquesta o altres taules. A la segona taula, apartada de la dels homes, hi van seure tota la resta de dames, pertanyents a diferents estaments, que també havien assistit a la cerimònia, i que potser eren "familiars" de la reina.

El document d'investidura no fa esment de cap altra sala però si ho fa l'inventari fet per l'abadessa Sobirana d'Olzet, que segueix descrivint la resta de les estances del palau començant per les de servei. Es diu que a la muceria, lloc destinat a guardar les carns, s'hi van trobar un matalàs, una màrfega, un coixí, teles que devien servir de llençols, i dues mantes de poc valor. A la paniceria, diverses peces de tela, unes balances, una màrfega i un matalàs, un parell de llençols i dues mantes. A continuació s'esmenta la cuina on hi havien diverses peces de ceràmica i altres atuells per cuinar: olles, greixoneres, paelles, ratlladores, pinces de ferro i de coure, a més de balances, morters de coure i marbre i calders d'aram. D'altres peces similars es guardaven en una habitació al costat de la mateixa cuina.

L'estança següent que es descriu és el celler. En aquesta s'hi van trobar tines, portadores i embuts de diverses mides, però es fa notar que tot estava buit. És en aquesta sala que es trobaven les divuit taules de fustes i els corresponents bancs abans ressenyats, a més de quatre estants igualment de fusta.

Ressenyades les estances de servei, l'inventari passa a la zona noble del conjunt, i es comença a fer descripció de l'habitació que sor Eulàlia Anzizu recollia en el seu llibre, i que va identificar com el lloc on la reina dormia que va definir d'una gran austeritat. Una lectura atenta d'aquesta sala i les següents permet veure que les estances particulars de la reina no es reduïen a aquesta habitació, sinó a d'altres següients. A més, la descripció d'aquest seu 
dormitori es va fer en dos apartats diferenciats. En el primer, efectivament, tal com recollia sor Eulàlia, només s'hi va descriure un llit de post, una màrfega i un parell de matalassos llistats amb bandes malves i blanques, un travesser llistat igual, una altra màrfega de poc valor, un altra matalàs i un altra traves$\operatorname{ser}^{32}$. Tota la roba de l'estança es va detallar més endavant, després de descriure les dues habitacions següents que també eren particulars de la reina. Un cop acabades aquestes altres sales es torna a l'habitació on dormia la reina i es diu que, a més del que ja s'havia descrit abans: Item, invenimus in dicta camera ubi dicta domina regina jacebat, ultra predicta iam supra scripta, hi havia nou seients amb el símbol heràldic de la reina i una conca d'aram, a més de roba diversa que consistia en diverses vànoves de poc valor, alguna de lli, llençols i un cobertor de seda d'un setial. ${ }^{33}$ Tot i que del conjunt no es desprèn una estança luxosa si s'observa que era confortable i segurament revestiria més sumptuositat si imaginem que part de les teles inventariades la podien haver ornat en algun moment: un sobrecel amb cortinatges pel llit, cortines brodades amb els signes reials a les finestres i algun tapis que acabaria de cobrir i ornar les parets a més de protegir-lo del fred.

Les estances particulars de la sobirana continuaven, almenys amb tres més. En una es diu que era on ella menjava amb les altres dames de la seva cort. Aquí hi havien vuit taules de fusta amb els seus bancs, tres estants i quatre seients, a més d'un armari de fusta i dues brandoneres verdes decorades amb els signes reials ${ }^{34}$.

Seguia a aquesta una altra sala que possiblement era ocupada pel personal de servei més directe de la sobirana ja que s'hi van comptabilitzar una màrfega $\mathrm{i}$ un matalàs de bort, dos fogons de ferro per escalfar-se, un de gran i un altre de petit, una brandonera, dues taules i un banc de fusta. A aquesta

\footnotetext{
32 "Item invenimus in quadam alia camera eiusdem palatii. Primum, unum lectum de postibus, et unam marficam, et unum par matalafiorum cum listis lividis et albis, et unum travesserium cum listis lividis et albis, et quandam aliam marficam modici valoris, et unum matalafium listatum diversis listis, et unum aliud travesserium". AHRMSMP, Lligall. Inventaris, Inventari pres la Ill. Sra. Abaddessa del Real Monastir, n. 137.

33 "Item, invenimus in dicta camera ubi dicta domina regina jacebat, ultra praedicta iam suprascripta, novem sitis cum signo regali et de Montecateno, et quandam vanovam ondadam panni lini quatuorum telarum et media, et quandam aliam vanovam botonadam modici valoris, et quandam aliam vanovam ondadam panni lini quinque telarum, et unum par linteaminum panni lini quolibet ipsorum quatuor telarum pectinis ampli, et quoddam linteamen magnum duarum telarum eiusdem pectinis modici valoris, et quandam vanovam magnam panni lini botonadam, quinque telarum eiusdem pectinis, et quandam conquam de aram, et unum par linteaminum trium telarum eiusdem pectinis, et unam cohopertam de siti de cirico, et quandam aliam cohopertam modici valoris". Cf. supra.

34 "Item, invenimus in sala in qua dicta domina regina simul cum aliis dominabus sua curia comedere solebat tempore quo vivebat, octo tabulas fustis cum earum capitellis, et tria stanna et quatuor sitis, et quemdam armarium fustis, et duas blandonerias virides cum signis regalibus et de Montecateno". Cf. supra.
} 
seguia encara una altra habitació on es van inventariar una "banyadora" gran i diversos utensilis d'aram i ferramentes diverses que servien per cuinar: aptos ad coquinadum, et quandam cassiam magnam ferri perforatam, et quandam calderiam de aram modici valoris.

Després d'aquestes estances que semblen les més privades de la sobirana, se'n segueixen descrivint d'altres possiblement ocupades per les dames de companyia més afins a la seva persona, ja que el mobiliari que s'hi descriu consisteix únicament en llits, matalassos i màrfegues acompanyats dels corresponents coixins. No es fa esment de la roba d'aquestes quatre estances que podria venir motivat pel fet que, a pocs dies de la mort de la reina, els domèstics que havien conviscut amb ella ja havien començat a recollit les estances per abandonar el lloc. Aquesta apreciació concorda amb el fet que la mateixa Elisenda havia disposat en el seu testament que els marmessors proveïssin els seus "familiars" de tot el que necessitessin durant el termini exacte de vuit dies: et quid interim omnibus de familia nostra providentia de bonis nostris per octo dies, nisi eis esset satisfactum in toto, eo quod eis legamus ${ }^{35}$.

En aquesta sala s'hi van trobar un seguit de vànoves de lli, cobertors de llana de bort, altres de pell o seda, i tovalloles blanques també de lli. A la mateixa habitació es guardaven d'altres peces d'ornamentació: tapissos negres, una tela de paret llistat amb bandes vermelles i morades de poc valor; dues cortines amb els distintius reials brodats sobre tela d'estamenya, i moltes d'altres cortines, algunes de llana, llistades de diferents colors o bé amb els signes reials, a més de diversos cobertors de seda per les taules i cadires. Tot això al costat d'un llit de posts, una màrfega de palla, dos bancals amb els signes reials i un tercer pintat de verd amb diverses decoracions figurades, una taula i un banc. Encara en una altra cambra s'hi van trobar recollides d'altres peces de roba de més qualitat: diversos coixins de seda, un sobrecel i cortines negres amb els signes reials i cobertors amb brodats de fil d'or que podien correspondre al parament de les estances reials dalt esmentades.

Sembla segur que totes aquestes peces d'ornamentació havien d'haver estat retirades de les diferents sales, el que explicaria la imatge d'extrema sobrietat de les habitacions, inclosa la de la mateixa reina.

Encara es fa esment d'una altre habitació, aquesta ja en el pis superior del claustre, on s'hi van trobar encara més peces de roba de llit, tapissos de diferents mesures i cortines; a més de matalassos, màrfegues i coixins; la majoria coberts amb teles de poca qualitat, però també se'n conservava alguna de seda i d'altres brodades amb fil d'or amb la que s'havien confeccionat

${ }_{35}$ AHRMSMP, Llibre de Privilegis i Donacions Reials, R/17, ff. 219-236; Perg. 94: Testament de la reina Elisenda. 
cortines i cobertors de coixins. També en aquesta estança s'hi guardava algun cofre i diferents peces de llautó.

És de remarcar l'esment que es fa d'una cambra destinada a servir de "cúria" de la reina. Allà s'hi va trobar un moble-escriptori de fusta de teca i un cofre que contenia llibres de paper que feien referència a negocis de la cúria de la reina. A banda d'aquests llibres que es conservaven encara in situ, l'inventari també recull que alguns documents provinents d'aquesta cúria com diversos pergamins que contenien els privilegis reials i episcopals concedits a la reina i d'altres d'assumptes d'importància, així com un bon nombre de cartes que es guardaven dins de bosses de tela, ja havien estat traslladats al dormitori del monestir, de la mateixa manera que s'havia fet amb part dels diners i les peces i joies que s'havien trobat a la capella particular de la reina. El conjunt d'objectes litúrgics i d'altres peces de valor, s'havien dipositat en un cofre. A l'interior d'aquest hi van trobar un calze i una creu de plata daurada, tots dos decorats amb esmalts i amb els emblemes heràldics de la reina, a més d'altres objectes tots ells de plata: una bacina, un salpasser, dos canelobres, dues canadelles i una capsa per les hòsties d'ivori i plata. Juntament amb ells, un missal de pergamí, i algunes taules de fusta pintades. A més d'aquest, encara altres dos cofres contenien més joies i robes de lli que devien haver servit a la capella.

Dues estances més completaren l'inventari: l'estable i el rebost. Al primer, on hi havia un mul de pel roig, també hi dormia l'atzembler de la reina que disposava d'un matalàs, un llençol, dues flassades de poc valor i una màrfega. Al rebost s'hi van trobar varies lliures de candeles i brandons de cera, a més d'estovalles, tovalloles i d'altres peces de tela guardades dins un armari de fusta. El mobiliari d'aquesta estança es completava amb un arquibanc, una caixa, unes brandoneres i una pastera de fusta.

El document va ser revalidat amb la signatura de tota la comunitat ja que la major part d'aquestes peces formaven part de l'herència que la reina havia fet de tots els seus béns al monestir.

Com es pot observar, si bé les peces decoratives i bona part de la roba ja havia estat recollida, els mobles sembla que seguien al seu lloc. Es pot apreciar fàcilment, que a banda d'un nombre considerable de taules, bancs i algunes cadires, repartides en estances determinades, principalment les de la reina, la resta de mobiliari consistia en taules, bancs, algun armari i, sobretot, llits de posts que anaven acompanyats d'altres matalassos i màrfegues que devien estendre's directament sobre el terra. La imatge que es desprèn de l'inventari és que al palau hi devien residir un nombre importat de persones, tot $\mathrm{i}$ això, el número de dames més properes a la reina semblarien poques, si es té en compte el nombre de llits enumerats, tot i que no seria estrany suposar, pels costums del moment, que al costat d'aquests llits, i directament sobre màrfegues 
al terra, hi poguessin dormir el personal de servei més directe. Igualment hem de pensar que no tot el personal havia d'estar en aquestes estances ja que, si tornem a rellegir el manament de la reina sobre el fet que s'enderroqués totum hospitium familia nostra et palatium eiusdem familia, sembla clar que, al costat del palau principal de la reina, hi havia d'haver un alberg per la resta del personal palatí que va ser enderrocat.

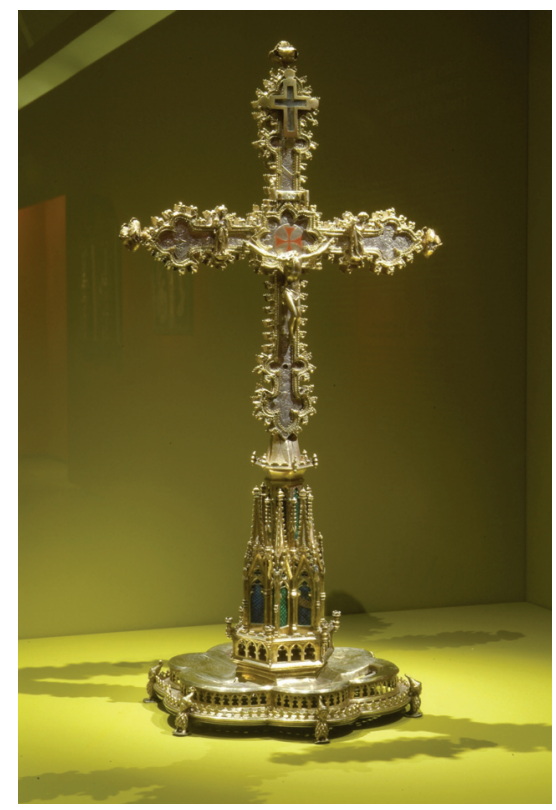

Fig. 8. Creu d'altar, formada per dues peces, que conté una relíquia. La creu, datada al segon terç del segle XIV, podria ser l'única peça que es conserva del tresor de la reina. Reial Monestir de Santa Maria de Pedralbes, Jordi Puig, 2004.

Malgrat que l'inventari fa una descripció de les sales de forma correlativa, podria ser aventurat donar per fet que totes les estances se succeïen en l'ordre en que estan descrites, tot i que en molts casos semblen tenir una lògica que així ho fa pensar. Hi ha un fet que mostra clarament que aquestes dependències es trobaven a dos nivells perquè en un moment determinat es fa esment del claustro superiori monasterii supradicti que pensem s'està referint a la terrassa superior de l'ala nord, on hi havia el dormidor de les monges i el "cor de dalt", per tant, en aquesta terrassa sembla que també hi podia haver hagut part del palau de la reina. La resta de les estances del seu palau i la dels seus "familiars", molt bé podien situar-se en part en aquesta mateixa terrassa 
superior, i en part en la inferior, corresponent al nivell del claustre, tal vegada, ocupant un segment de l'ala oest on avui es troben el refetor de la comunitat i tres petites sales al dessota de l'esmentada "sala de la reina". Curiosament, no es fa esment de la "capella particular de la reina" malgrat que s'hi fa referència en relacionar els diners, joies i ornaments que s'havien traslladat ja al dormidor. Igualment es coneix el nom del seu capellà major, Arnau de Carbessí, a qui la reina va deixar una suma considerable de diners en el seu testament, només equiparable a la llegada als seus familiars més directes ${ }^{36}$.

El més personal que l'inventari ens proporciona de la reina, és l'inventari de les seves joies, entre les que trobem a faltar la corona reial que li havia estat regalada pel rei en els seus esponsalicis, després que aquest l'adquirís al seu germà Ot. No obstant, és segur que la reina la va conservar i deixar en herència a la comunitat que posteriorment va vendre al vescomte de Cardona, per la qual van obtenir quatre florins d'or, tal com queda detallat en el llibre de marmessoria. ${ }^{37}$ També es fa referència a algunes peces d'orfebreria i la menció que posseïa algunes taules pintades que devien ser devocionals atès que estan relacionades amb la seva capella. Pel que fa als hàbits de lectura poc en podem deduir ja que l'únic esment que es fa d'un llibre és un missal que després passaria a la comunitat.

La imatge del palau de la reina que es desprèn de l'inventari, és el d'una veritable cort que comptava amb una vintena d'estances, de les quals almenys cinc estaven destinades a ús personal de la sobirana i les dames de companyia més properes, quatre mes semblen també de personal del seu entorn, i la resta, tenien funcions diverses. Igualment, cal notar que posseïa una estança que complia expressament la funció de cúria i una capella personal.

En relació a la quantitat de roba inventariada contempla una gran varietat, que va des de roba de llit, fins coixins, cortines, tapissos de paret i cobricel. Igualment s'esmenta que certes estances disposaven d'aparells per escalfar-les. Si això li afegim un nombre important de peces de vaixella de plata i altres materials, obtenim una visió de la reina i del seu palau que no sembla allunyar-se massa del d'altres estances de palaus reials de la cort catalana d'aquell període.

No hem de veure en aquest confort i certa sumptuositat un contrasentit amb una declarada pietat i devoció franciscana que la sobirana mostrava amb actes caritatius i donatius, tal com recull inclús el seu testament i disposicions per les seves exèquies, però que anava en la línia del que era propi i s'esperava d'una reina que no va renunciar mai a la seva posició.

${ }^{36}$ Copia del testament de la reina Elisenda. AHRMSMP, Llibre de Privilegis Reials, P/17.

${ }^{37}$ AHRMSMP, Testamentaria. Marmessoria de la Reyna Dona Elisendis, T/5. 
Però on més declaradament s'observa el seu franciscanisme és en el renovat interès que al llarg de la seva vida va mostrar per dotar el monestir, la comunitat femenina, i també la masculina que estava al servei d'aquesta, de tot el necessari pel seu manteniment en el present i en el futur. Les diferents ordinacions que va anar fent al llarg de la seva vida, sempre van anar destinades a augmentar les rendes del monestir si bé a canvi que la comunitat tingués entre les seves prioritats la de pregar per l'ànima de la reina, el seu espòs,el rei Jaume i la resta de la seva família per sempre més. Igualment, la reina es reservava el dret d'abolir o canviar les seves donacions sempre que ho creies necessari, Davant d'això, la comunitat no va ser plenament propietària i facultada per decidir sobre els seus assumptes fins després de la mort de la reina ocorreguda segons el llibre de defuncions del monestir, el 19 de juliol del 1364, malgrat que el llibre de marmessoria el retarda fins el dia 24, a les vespres de la festivitat de sant Jaume ${ }^{38}$.

En aquell any, va coincidir també la defunció de la segona abadessa del monestir, sor Francesca Saportella i Pinós (25 d'abril de 1336-25 de maig de 1364), reneboda de la reina per línia materna que va morir quasi dos mesos abans que la reina. Francesca era filla de Sibilla de Pinós, casada amb Bernat Guillem de la Portella, cosina de la mateixa reina. Al mateix temps, la nova abadessa era cosina d'altres dues nobles del cercle cortesà de la reina, Constança i Sibil·la de Cardona i Pinós, casades amb el noble Gilabert de Cruïlles, la primera, i amb el comte Ramon Roger II de Pallars, la segona. Serien les filles d'aquestes dues, Constança de Cruïlles i Violant de Pallars, les que, en ingressar com a religioses al monestir, constituïren juntament amb l'abadessa sor Francesca Saportella, el cercle familiar més proper a la reina, amb càrrecs importants en el regiment de la comunitat. Aquesta proximitat a la figura de la reina, porta a plantejar-se el fet de en quina mesura el projecte del monestir responia a una decisió única i personal de la reina, i si aquest projecte era original i compartit per la comunitat i el cercle cortesà que li era més proper.

\section{LA CONSTRUCCIÓ DEL MONESTIR, UNA IDEA COMPARTIDA?}

La reina havia dictat el seu testament l'11 d'abril, un mes abans de la mort el 25 de maig de l'abadessa Francesca Saportella. Al testament encara contemplava una donació de 300 sous per ella que no es van poder fer efectius per la seva prompta mort. En consequiència, encara en vida de la reina i amb

${ }_{38}$ AHRMSMP, Llibre de Defuncions, D/1; Testamentaria. Marmessoria de la Reyna Dona Elisendis, $\mathrm{T} / 5$. 
l'existència del palau, la nova abadessa, sor Sibil·la de Queixans va dur a terme un inventari del monestir, el primer que es coneix, en un moment en que el conjunt religiós ja devia estar força avançat i en algunes parts, com l'església, pràcticament enllestit.

Com en el cas del palau de la reina, també sor Anzizu va fer esment en el seu treball d'aquest inventari que qualifica de notable, i és que certament es tracta d'un registre exhaustiu de totes les estances i els bens que hi va anar trobant. Amb posterioritat a la mort de la reina, algunes dels objectes que havia deixat en herència a la comunitat, van ser inclosos en un annex a aquest document ${ }^{39}$. L'inventari va començar el dia 6 del mes de juny de l'esmentat any 1364 que coincidia amb un dijous.

Tal com es diu a l'encapçalament, la relació de béns es va dur a terme en un "qüern per capítols", és a dir, en un quadernet dividit per apartats. Cada apartat o capítol va precedit pel nom de la sala i la paraula "robes" que es fa servir com a genèric per designar tots els béns que es troben en aquella estança. No és el nostre interès aquí descriure en detall els béns que s'esmenten que ja ha estat fet en d'altres ocasions, sinó la configuració de la planta del monestir que es dibuixa. Tot i les precaucions sobre la correlació de les estances inventariades que ja hem fet notar pel que feia al palau de la reina, en el cas del monestir, en haver-se conservat fins al present la planta original del cenobi, podem assegurar quasi amb total certesa que es va anar resseguint la planta construïda.

La primera estança en inventariar-se va ser la sagristia del monestir. De la relació del que aquí s'esmenta, cal destacar pel que fa al nostre interès l'anotació que es fa sobre una capsa d'argent en què se tenen lo Corpus Christi en l'esgleya defores sobre l'altar mayor, pel fet que és indicatiu, com altres evidencies anteriors feien preveure, que en aquesta data l'església estava perfectament acabada.

Un cop enllestida la relació dels bens d'aquesta estança que era la més rica en ornaments, sor Sibil·la de Queixans fa esment d'una habitació on s'hi devien allotjar les germanes servicials que estaven autoritzades a sortir del monestir les companyes de fora. Presumiblement, aquest espai havia d'estar prop de l'entrada del monestir, per tant, semblaria que l'inventari va iniciar-se a la sagristia que per la seva funcionalitat havia d'estar prop del presbiteri, a l'ala est del complex i, tal com és ara, també prop de l'entrada del

\footnotetext{
${ }^{39}$ Sor Eulàlia va fer una transcripció de tota la primera part del document que contempla tots els objectes de més valor que posseïa la comunitat i que es trobaven a la sagristia i església. Contràriament, no va fer cap esment de la resta del document que ens serveix pel nostre propòsit de conèixer l'estructura del monestir. E. Anzizu, Fulles, pp. 76-87. AHRMSMP, Lligall 137, Inventaris.
} 
monestir, per anar continuar des d'aquest punt, cap a l'ala sud. Potser, un cop ja en aquesta ala, s'hi trobaria el celler robes del seller e al vi qui aquí és que, segurament, es localitzava a la terrassa inferior, prop dels horts, tal com també és actualment. De ser correcta aquesta ubicació, seria en aquest punt, però a nivell superior de claustre, on anys més tard, s'hi bastiria l'actual sala capitular. Cal recordar aquí que, malgrat que la comunitat ja disposava en aquells primers moments dels recursos econòmics necessaris per edificar aquesta estança tan important per la vida comunitària gràcies a un llegat testamentari, no sembla que ho portés a terme fins a començament del segle següent, el que fa pensar que tal vegada l'espai de l'actual sala capitular estava ocupat en aquelles dates per un primitiu cos que podia ser anterior a l'edificació del propi monestir, potser el "seller" al qual aquí es fa esment.

A continuació es passa a relacionar el magatzem de l'hortolà robes que té l'ortolà qui serveixen a la orta, $\mathrm{i}$, tot seguit, la infermeria, robes de la enfermeria, que disposava de vint-i-un llits de post, a més d'un nombre considerable de matalassos, vànoves i llençols i d'altres utensilis propis del seu ús com bacins de llautó, alambins i dos fornells grans de ferro que servien per fer foc en aquesta zona. Tot aquest seguit d'estances es poden resseguir perfectament avui al llarg d'aquesta ala si bé a dos nivells, l'inferior amb les estances de servei prop de l'hort i la infermeria al de sobre, a nivell de claustre encara que l'actual edifici correspongui a la refecció de final segle XVI per bé que conservant les restes de l'anterior al dessota.

La següent estança de la qual es fa esment és la cuina, robes qui servexen a la cuyna. Aquí s'hi enumeren un bon nombre d'utensilis domèstics propis per la cocció dels aliments per passar a continuació, al refetor, robes del refetor. Malgrat que som conscients que els espais que avui tenen aquesta funció són posteriors, no sembla haver dubte que han mantingut la seva funcionalitat inalterable des del moment de la fundació fins al present, per la qual cosa, podem tenir la quasi certesa que s'havia passat a descriure les estances que ocupaven l'ala oest. Un cop acabada d'enumerar aquesta sala ja només es fa esment de l'estable, robes ab bèsties qui són comanadas al traginer i el pastrim, robes e forment e farina qui són al pastrim. Aquests dos darrers espais devien estar propers a la mateixa cuina i al refetor, tal com ens consta que seria en períodes posteriors. L'inventari del les estances acaba en aquest punt ja que el document continua enumerant les rendes i censals que el monestir rebia en aquells anys.

Si observem l'actual monestir veiem que, a nivell de claustre, el refetor i la cuina només ocupen una part de l'ala oest, i a continuació s'hi troben les tres sales conegudes com "el rebostet", sota de l'anomenada "sala de la reina". Molt possiblement, aquesta mateixa distribució era la que ja s'havia configurat en vida de la reina Elisenda i l'abadessa Francesca Saportella, per 
la qual cosa, arribat a aquest punt, el monestir convergia amb les parets del palau de la reina, just abans que aquest fos enderrocat, conservant-se únicament aquesta part del palau que encaixava amb l'angle entre el refetor i el dormidor que, emplaçat sobre la terrassa superior de l'ala nord, curiosament, no és esmentat a l'inventari.

En quin moment el monestir va tenir prou perímetre edificat per permetre a les religioses poder disposar del conjunt d'estances que aquí descrivim, no ho podem determinar per ara amb total certesa però si aventurar una hipòtesi força plausible a partir de diversos indicis.

Com hem dit, la reina es va reservar ja en la primera de les seves ordinacions, la capacitat de canviar-ne els termes i així ho va fer en diverses ocasions, la primera el 4 de novembre de l'any $1334^{40}$. Aquesta segona fundació de la reina és molt important en la mesura que reflecteix un punt d'inflexió en la vida de la comunitat, no és perquè sí que és la més llarga de les quatre que va emetre al llarg de la seva vida. Durant els anys que havien transcorregut des de la fundació del monestir i primera ordinació de la reina, el monestir havia vist augmentades les seves rendes de forma considerable amb el patronatge sobre noves vicaries, l'obtenció dels drets perpetus sobre la duana del castell de Càller a Sardenya, com a privilegi concedit pel rei Alfons, i més donacions pecuniàries per part de la reina amb obligació de ser invertides en la compra de censals i violaris. Aquest augment considerable de les rendes havia de permetre que el monestir pogués acollir en endavant un nombre major de religioses fins arribar a seixanta que podien entrar sense dot i deixava la porta oberta a que fossin més si aportaven els béns necessaris pel seu manteniment. De fet nombroses registres notarials donen fe que un gran nombre de religioses entraven aportant una dot en forma de renda. A totes aquestes religioses s'hi havia de sumar el servei necessari pel manteniment de la casa. Igualment, es feia esment que el nombre de capellans podien passar de quatre a deu i es mantenien els quatre frares que a partir d'aquest moment, sembla que van passar a residir al convent de davant del monestir de les dones, l'anomenat conventet. Amb aquest augment de persones, no hi pot haver dubte que el monestir havia d'estar pràcticament enllestit en la seva configuració i amb les estances necessàries per acollir-les $i$ atendre les seves diverses necessitats.

D'altra banda, la reina estipulava en aquesta segona ordinació, que una de les obligacions d'aquests capellans era que cada setmana a un d'ells li

\footnotetext{
${ }^{40}$ Aquesta segona ordinació de la reina, la més extensa de les quatre que va dictar al llarg de la seva vida, va ser redactada en llatí, sobre quatre pergamins units entre sí. A causa de la seva rellevància, el document va ser transcrit $\mathrm{i}$ traduït al català en diverses èpoques $\mathrm{i}$, al mateix temps, se'n van fer extractes en diversos llibres inventaris. AHRMSMP, Segona fundació de la Reina, Perg 1000; Fundació segona del monestir de Pedralbes, F/24 A, Segona fundació. Fundacions reials. Lligalls, n. 124, vol. F.
} 
correspongués oficiar la missa a l'altar major mentre la resta ho havia de fer a les capelles laterals. Segons això, s'hauria de concloure que l'església havia d'estar pràcticament enllestida, no obstant, si es té en compte la tècnica emprada en la construcció dels grans edificis gòtics catalans, els murs de tancament de la nau s'haurien anat aixecant no per trams, com en altres àrees geogràfiques, sinó a partir de la construcció d'una banqueta de fonamentació llarga que abastaria tot el perímetre de la nau, sobre de la qual s'anirien aixecant les filades de pedra i reble fins a l'alçada del coronament de les naus laterals, amb els seus òsculs, per continuar avançant fins a assolir les obertures dels arcs de les finestres i l'arrencament de la volta. En aquest punt, es podia haver cobert la nau amb una plataforma de fusta que permetés al culte al seu dessota mentre es continuava la cobertura de la nau amb la volta i les claus ${ }^{41}$. Podria ser doncs, que malgrat el que es disposa la nau encara no estes enllestida en la seva totalitat, tot i així, no sembla que es tardés massa més en el seu acabament definitiu si tenim en compte el resultat de l'estudi dut a terme per Natàlia Baqué sobre la iconografia de les claus de volta que apunten a un espai de temps molt curt, entre el $1341 \mathrm{i}$ el $1348^{42}$.

Ens aturem en aquest punt constructiu del monestir perquè justament aquestes dates són significatives per passar a analitzar la implicació que la reina Elisenda i el seu entorn més immediat, començant per la mateixa abadessa sor Francesca Saportella podien haver tingut en les obres. Si tenim present que aquesta abadessa va assolir el càrrec l'any 1336, ens adonem que durant els anys decisius en el que el monestir adquireix la seva fesomia i es consolida, el conjunt va estar regit pel tàndem de la reina des del seu palau, i la seva neboda, des del monestir. I a elles dues es deuen les peces cabdals que defineixen i exemplifiquen tot el discurs programàtic del monestir i que són una mostra clara que compartien una mateixa devoció franciscana. Ens referim a la tomba que la mateixa sobirana es va fer edificar en vida al mateix monestir i el conjunt de pintures murals que l'abadessa Francesca Saportella va encarregar per ornar la seva capella privada dedicada a l'arcàngel sant Miquel.

En relació al sepulcre funerari de la reina, no disposem del nom de l'artista o taller que la va dur a terme, ni tampoc la data exacta, però si sabem del cert que quan la sobirana va dictar el seu darrer testament, aquest ja estava enllestit tal com ella recollia: coram altari scilicet maiori eiusdem ecclesia in monumento quod nos ibi habemus volentes et mandantes ac etiam ordinantes ${ }^{43}$.

${ }^{41}$ Remetem a l'estudi de les fonts documentals en relació a la construcció dels vitralls de l'església. A. Castellano-Tresserra, Notícies documentals entorn dels vitralls, pp.14-15; també, F. Bazzochi, Las vidrieras góticas, pp. 24-37.

${ }^{42}$ N. Baqué, Les claus de volta, pp. 59-105.

${ }^{43}$ AHRMSMP, Llibre de Privilegis Reials, P/17. Còpia del testament de la reina Elisenda de Montcada. 
No entrarem a detallar tot el que s'ha dit sobre la construcció d'aquesta tomba, recordem sí, la unànime opinió que el conjunt devia ser obra d'un dels tallers que en aquell moment treballaven a Barcelona, apuntant-se al mestre francès Pere de Guines com el més probable, encara que potser també hi poguessin haver intervingut d'altres artistes com Aloi de Montbrai ${ }^{44}$, el que ens interessa ressaltar és la proximitat entre la realització d'aquest projecte i el de les claus de volta de l'església que segons un estudi podrien adjudicar-se al mateix Pere de Guines o taller, el que li donaria una datació al voltant del 1340 com hem dit al començament ${ }^{45}$. Si s'observa la configuració de la tomba de la reina, dual, amb la caixa del sepulcre de marbre que travessa el propi mur, es pot deduir que el conjunt funerari va ser concebut i ideat de forma paral-lela a la de pròpia construcció de l'església. El seu emplaçament entre dos dels contraforts de l'àbsis, l'espai més emblemàtic de l'església, en la paret del cantó sud que també serveix de tancament al claustre del monestir contigu, respon, sens dubte, a una idea ben concebuda i pre-concebuda.

Si bé com s'ha dit aquesta tomba ha esta molt estudiada des del punt de vista artístic, no ha estat fins fa poc que s'ha analitzat des de la perspectiva de la seva representativitat dins el conjunt de l'església i del monestir, a càrrec de la historiadora Eileen McKiernan, que n'ha ressaltat la seva excepcionalitat en aquest sentit. ${ }^{46}$ En total sintonia amb les seves apreciacions ja vam apuntar en el nostre estudi sobre patronatge femení, com aquesta voluntat de la reina de deixar plasmar tot els seus ideari de vida i devoció franciscana en la seva tomba, tenia uns clars precedents en d'altres reines properes com Sança de Mallorca al convent de Santa Clara de Nàpols i, potser també, santa Isabel de Portugal, a Santa Clara-A-Vehla que també havien reflectit la seva religiositat fundant convents de clarisses de forma semblant a Elisenda ${ }^{47}$.

La tomba de la reina Elisenda i les claus de volta que coronen el temple semblen construccions coetànies com també ho havia de ser la decoració de la capella de Sant Miquel que l'abadessa Francesca Saportella encarrega al mestre Ferrer Bassa, per primera vegada el 1343 i per segon cop, el 1346. L'italianisme d'aquestes pintures, allunyades del panorama artístic del seu

\footnotetext{
44 Mentre Pere Beseran s'inclina per Pere de Guines com l'autor de l'obra, Francesca Español creu que hi van intervenir tres mestres un dels quals seria efectivament Pere Guines. També Maria Rosa Manote i Rosa Terés creuen que l'autoria podria ser de Pere de Guines, però també, de Jaume Cascalls o/i Aloi de Montbrai, inclinant-se més per aquest darrer mestre. P. Beseran, Un taller escultòric, pp. 215-245; idem, Noves aportacions a l'entorn del sepulcre, pp.87-99; F. Español, El gótico catalán, pp.7071; M.R. Manote, R.Terés, El mestre de Pedralbes, pp.181-182.

${ }_{45}$ N. Baqué, Les claus de volta, pp 59-105.

${ }^{46}$ E. McKiernan, Reception, Gender and Memory, pp. 309-354.

47 A. Castellano-Tresserra, La reina Elisenda de Montcada i el monestir, pp.109-131.
} 
entorn per aquelles dates, vinculen molt estretament l'obra amb els mestres italians del moment que no només empràvem tècniques innovadores i uns trets estilístics propis sinó que recollien un component devocional clarament franciscà d'arrels i formes d'expressió clarament italianes. Ja hem dit, en línea amb el que apunten també d'altres estudiosos com Rosa Alcoy pel que fa al cicle mural i Pere Beseran pel que fa a la tomba, que cal cercar els paral·lels més directes de les obres de Pedralbes a la cort angevina de Nàpols. Comprovem com el repertori iconogràfic de la capella de sant Miquel: els Set Goigs de la Verge i el cicle de la Passió de Crist es tornen a trobar també a l'església. Efectivament s'observa, com ja hem dit, com les claus de volta presenten els diferents goigs de la Verge fins arribar a la seva coronació a l'absis, mentre que la passió de Crist queda representada en l'escena de la crucifixió que decora el vitrall central de la rosassa del cor de dalt. Hem de fer menció aquí de l'encàrrec que en el seu moment la mateixa abadessa, Francesca va fer al fill del pintor Ferrer Bassa, Arnau, perquè decores amb un mural l'entorn d'aquesta rosassa, amb la representació de l'arbre de la vida. Malgrat que mai s'hagin trobat testimonis de que efectivament aquest mural s'hagués arribat a portar a terme, no obstant, cal ressenyar que l'esmentat inventari de l'any 1364 que l'abadessa Sibila de Queixans va dur a terme, a la sagristia es fa esment d'unes taulas en les quals és pintat l'arbra de vida e à.y encastada de la Vera Creu ${ }^{48}$. No se'n diu l'autor, però no hem d'oblidar l'encàrrec fet a Arnau Bassa que podia haver convertit un mural en unes taules tot mantenint el tema. Fos qui fos l'autor d'aquestes "taules", el que ens interessa aquí ressenyar és que s'especifica que havien estat propietat de l'abadessa Francesca Saportella i que aquesta hi havia fet representar justament, "l'arbre de la vida", a més de contenir un fragment de la veracreu. Molt probablement, aquestes taules es venerarien al cor de les monges, sota el rosetó esmentat.

Aquest conjunt de testimonis mostren una completa compenetració en la concepció del projecte del monestir entre la reina Elisenda i l'abadessa Francesca Saportella que van anar plasmant el seu projecte en els anys del seu regiment. No obstant això, pensem que no només elles van participar en la concepció i posterior plasmació d'aquest gran projecte, també algunes nobles s'hi van afegir.

El primer testimoni d'una d'aquestes nobles que van participar també en el projecte del monestir, el trobem en Constança de Cardona, enterrada al monestir en un petit sepulcre que, a imitació del de la reina, traspassa la paret de l'església i es pot observar des de la capella de sant Pere per l'interior de l'església, i al costat de la reina pel cantó del claustre on es pot llegir el seu

\footnotetext{
${ }^{48}$ AHRMSMP, Lligall 137, Inventaris .
} 
epitafi. Per aquest podem saber que aquesta noble va morir el 1325, abans que s'iniciessin les obres del monestir, tot fent donació d'una suma importants de diners per a la construcció de la Sala Capitular, tot i que, com ja hem dit abans, es va tardar encara uns anys en bastir la nova sala. El cas de Constança de Cardona que havia ingressat de gran en el convent de Santa Clara de Barcelona on devia morir i d'on es van traslladar les seves restes a Pedralbes, és paradigmàtic de la implicació d'altres nobles i religioses que, juntament amb la reina i l'abadessa, van donar forma al projecte del monestir de Pedralbes.

No només ella, d'altres nobles i religioses es van implicar en aquells moments com a benefactores del nou monestir com ho recull l'esmentat inventari del 1364 que especifica que algunes de les peces que s'inventariaven havien estat encarregades per diverses religioses. També el llibre de defuncions recull donacions diverses a favor de la nova fundació i si bé en alguns casos no s'especifica, en molts d'altres, els objectes anaven destinats a magnificar el lloc que els era més propi, el "cor de dalt" o "cor de les monges", però també havien de servir per donar major rellevància a certs altars de l'església, com el major dedicat a la Verge, o el del Sant Crist, pels que algunes religioses van fer donacions per fer-hi cremar ciris en certes celebracions litúrgiques.

\section{CONCLUSIONS}

Com hem dit en un inici, calen un bon nombre d'estudis per tal de poder donar respostes conclusives a l'interrogant de si el patronatge artístic de les reines, abadesses i d'altres dones de la noblesa podien ser comparables entre si, però la informació que aporta el monestir de Pedralbes en aquest sentit, és certament rellevant.

No sembla haver-hi cap dubte, com ja hem apuntat en d'altres ocasions, que la fundació del monestir de Santa Maria de Pedralbes va respondre bàsicament a una idea de la reina mateixa, que en va ser la principal instigadora i que, probablement, en va supervisar l'execució per tal que respongués al seu projecte vital i devocional. Malgrat l'originalitat que en diversos aspectes mostra el monestir de Pedralbes, no hem de deixar de banda, la influència que sobre Elisenda i els seus col-laboradors més directes, havien de tenir d'altres projectes que s'estaven executant per aquells mateixos anys amb els quals s'establia una clara relació.

De forma coincident, Núria Jornet, en el seu anàlisi sobre els orígens del primer monestir de clarisses de Barcelona, recull que el mateix any 1326 , quan es col-locava la primera pedra a la capçalera de l'església del futur monestir de Pedralbes, també s'iniciaven els treballs del claustre del monestir de clarisses de Sant Antoni de Barcelona, d'on sortiren les religioses que fundari- 
en Pedralbes. Tot i que les primeres notícies documentals sobre aquest claustre es remunten al 1254, sembla que no seria fins aquest moment del primer quart del segle XIV, que el monestir endega la seva construcció, seguin un model de columnata i arcuacions que mostrava una clara similitud amb el de Pedralbes $^{49}$. El paral-lelisme és una mostra més de les estretes relacions existents entre els dos monestir de clarisses de Barcelona en un inici.

No obstant les coincidències estilístiques en la construcció de certs àmbits dels dos monestirs barcelonins i en la concepció del conjunt de les edificacions que d'altra banda responen a la normativa pròpia dels grans conjunts monacals no sembla que el projecte que va originar la fundació del convent mare tingui a veure amb el de Pedralbes, ben al contrari, els possibles parallels en aquest sentit, cal cercar-los més, com ja hem apuntat en altres ocasions, en d'altres cenobis fundats per reines properes a la mateixa reina Elisenda per via de parentiu i que, per tant, ella devia conèixer prou bé ${ }^{50}$. Ens referim al convent de Santa Clara de Nàpols, promogut per la reina Sança (1286-1346), esposa del rei Robert i cosina del rei Jaume II, que es trobava en fase de construcció en els mateixos anys que Pedralbes i sembla ser un clar paral·lel pel que fa al seu programa edilici, però, sobretot, en la concepció devocional que hi havia al darrera, una manifesta pietat franciscana que la reina Sança experimentava de forma molt radical i que es plasmava en la concepció de certs espais i en les representacions pictòriques que els ornaven. Aquestes obres, a les que fa referència l'estudi de Caroline Bruzelius, eren executades per artistes o tallers que empraven les tècniques artístiques innovadores sorgides als tallers florentins i sienesos, i que, en molts casos, responien a encàrrecs dels propis convents mendicants que es construïen de bell nou en aquells anys.

Aquestes mateixes tècniques també les trobem en els murals de la capella de Sant Miquel, encarregats per l'abadessa Francesca Saportella, com a espai personal d'oració, i que plasmen en el seu repertori iconogràfic, una especial devoció franciscana basat en la vida de Crist i el cicle de la passió, i els goigs de la Verge, tal com un franciscà, Joan de Caulibus, va plasmar en el llibre de la Vita Christi que va esdevenir un gènere, justament per a la contemplació i meditació d'una monja clarissa. Uns murals semblants li podien haver servit de referent a sor Francesca a l'hora d'encarregar aquestes pintures, el cicle de la passió que revestia els murs dels cor alt del convent de Santa Maria

49 N. Jornet, El monestir de Sant Antoni de Barcelona, p. 94. Aquest plànol es va dur a terme poc abans que el monestir, molt malmès pel setge i l'assalt que les tropes borbòniques van infringir a la ciutat de Barcelona, el 1714, en el decurs de la guerra de successió espanyola, fos enderrocat. L'esment de la construcció del claustre en aquest any 1326, el recull el cronista del monestir, Sebastià Roger, qui diu que a més també es bastia el dormidor en el mateix moment.

${ }^{50}$ A. Castellano-Tresserra, La reina Elisenda de Montcada i el monestir, pp. 109-131. 
Donna Regina a Nàpols, fundat per la reina Maria d'Hongria i protegit per la reina Sança i que semblen inspirats en el mateix llibre, tal com analitza Adrian S. Hoch ${ }^{51}$.

A banda dels murals esmentats, la influència italiana es manifesta en molts altres elements constructius i ornamentals de Pedralbes com és el cas dels vitralls que ornen la capçalera de l'església i part de la nau ${ }^{52}$.

Però, igualment, havia d'influir notablement sobre la reina, el projecte que la reina Isabel de Portugal (1271-1336), esposa del rei Dionís i germana del rei Jaume II, cunyada per tant de la mateixa reina Elisenda, estava portant a terme en el convent de Santa Clara-A-Vehla de Coimbra. També en aquest cas, la reina devia tenir molt present la figura d'aquesta seva parenta d'una marcada religiositat i aureola de santedat, que plasmava en les obres del convent que ella dirigia des del seu palau emplaçat al costat mateix del cenobi, al que ella s'havia traslladat un cop ja vídua. Tal com exposa A.M. S.A. Rodrigues en el seu article esmentat, això li permetia supervisar directament les obres que es duien a terme al convent, exposant directament els seus desitjos i esmenant allò que no s'hi ajustava, com recull un relat que es va fer sobre la seva vida per a optar a la seva beatificació $^{53}$. La presència del palau al costat del monestir, i la manera d'actuar de la reina Isabel, són un clar referent d'Elisenda pel que fa a les seves actuacions al monestir de Pedralbes i mostren la real possibilitat que la reina exercís i dirigís directament els projectes que promocionava. Com ja hem fet referència, tant una com altra reina havien d'estar en la ment d'Elisenda quan aquesta devia pensar i dissenyar la seva tomba on resumeix el seu projecte vital, en les dues efígies de la seva persona que va fer esculpir sobre la seva tomba, a banda i banda de la paret que separa l'església del claustre. La representació com a sobirana per la banda de l'església, amb el mantell i tots els atributs reials, encaixa perfectament amb la imatge que d'ella ens ofereix l'inventari del bens que va deixar i la successió de les estances que conformaven el seu palau: una austeritat no desproveïda de tot el rang que corresponia a un palau cortesà d'una reina que mai va renunciar al seu estatus per ingressar al monestir com a religiosa. Cal notar que la reina va conservar sempre la seva corona reial, com altres sobiranes que després deixaven a les seves hereves com a símbol de categoria i prestigi

51 A.S. Hoch, The "Passion" cycle, pp. 129-153. Sobre la influència que el llibre de la Vita Christi atribuït a Joan de Caulibus pugui haver tingut sobre la representació de la capella de Sant Miquel ja n'hem fet referència en el nostre estudi anterior, A. Castellano-Tresserra, La reina Elisenda de Montcada i el monestir de Pedralbes, pp. 127-130.

${ }_{52}$ F. Bazzochi, Las vidrieras góticas, p. 29.

53 A.M. S.A. Rodrigues, The treasures and foundations of Isabel, Beatriz, Elisenda and Leonor, p. 925. 
social, però a diferència d'aquestes, l'absència de descendència reial va fer que Elisenda la donés en herència al monestir per, finalment, ser venuda i suposar un ingrés econòmic pel cenobi ${ }^{54}$.

$\mathrm{Si}$ és ben segur el paper de la reina com a principal promotora del monestir, també ho és el fet que el seu projecte va ser compartit des d'un bon començament per la comunitat, que va veure condicionat el propi espai del monestir per la presència del palau de la reina. La imatge de la tomba de la reina pel cantó del claustre, com a penitent, presidia el recinte. Tal com assenyala Eileen McKiernan, l'emplaçament de la tomba amb doble cara en el presbiteri i el claustre de Pedralbes responia, de forma semblant a com passava a Santa Clara de Nàpols, al desig de cercar una solució a les restriccions que imposava la clausura. Mentre des del cor emplaçat als peus de l'església, les religioses podien seguir l'eucaristia però disposaven d'una visió esbiaixada de la tomba de la reina, des del claustre n'obtenien una visió completa. La solució de Pedralbes, de dues efigies diferenciades de la reina, pensada per a dues audiències diferents, representa una gran innovació segons aquesta autora.

Les diverses donacions de les religioses fundadores a favor del monestir, per dotar-lo d'ornaments, exemplifica la seva implicació en el projecte. És a partir de l'elecció de sor Francesca Saportella, neboda de la reina, que coincideix en el moment en que el monestir assoleix la seva configuració plena, quan millor s'evidencia que les dues figures es mouen per un mateix ideal tal com queda reflectit en el programa iconogràfic de l'església, en correspondència amb el conjunt mural que decora la capella de Sant Miquel.

No només elles, com ja hem apuntat, d'altres dones de la noblesa, algunes que formen part de la cort de la reina i d'altres que ingressen a la comunitat com a religioses, en algun cas, filles de les anteriors, secundaran i acabaran de donar forma al projecte, tal com en deixen constància les múltiples donacions que van fer a favor del monestir ${ }^{55}$ que exemplifiquen la seva implicació també en el projecte. En el cas de Pedralbes, doncs, es pot assegurar que, el projecte reial no va diferir en cap moment i va ser compartit, tant per la comunitat com per les dones nobles que les acompanyaven.

54 Sobre la circulació de joies i objectes devocionals entre mares i filles o entre parentes, com a símbol de prestigi social, remetem a l'article de l'esmentada autora, ibidem, p. 913.

55 A. Castellano-Tresserra, Pedralbes a l'edat mitjana, pp. 220-222. 


\section{BIBLIOGRAFIA CITADA}

Anzizu, Eulàlia, Fulles Historiques del Real Monestir de Santa Maria de Pedralbes, Barcelona-Sarrià, 1897 (1a. edició); Barcelona, Publicacions de l'Abadia de Montserrat - Monestir de Pedralbes, 2007 (reed. facsímil).

Baqué, Natàlia, Les claus de volta de l'església de Santa Maria de Pedralbes, dins Balasch, Ester; Español, Francesca, Elisenda de Montcada. Una reina lleidatana i la fundació del Reial Monestir de Pedralbes, Lleida, Publicacions dels Amics de la Seu Vella de Lleida, 1997, pp. 59-105.

Bazzochi, Flavia, Las vidrieras góticas mediterráneas: composición química, técnica y estilo. El caso concreto de Barcelona y Siena en el siglo XIV, Barcelona, Universitat de Barcelona, 2012 (tesi doctoral). http://www.tdx.cat/handle/10803/97218.

Bazzochi, Flavia, Las vidrieras góticas: estado de la cuestión y fuentes documentales, dins Els vitralls del monestir de Pedralbes i la seva restauració, Barcelona, Museu d'Història de Barcelona, 2011, pp. 24-37.

Beltrán de Heredia, Julia, Terminologia i ús dels atuells ceràmics de cuina a la Baixa Edat Mitjana, dins Del rebost a la taula. Cuina i menjar a la Barcelona gòtica, Barcelona, Museu d'Història de la Ciutat, 1995, pp. 46-56.

Beseran, Pere, Un taller escultòric a la Barcelona del segon quart del segle XIV $i$ una proposta per a Pere de Guines, "Lambard: estudis d'art medieval" 6 (1991-1993), pp. 215-245.

Beseran, Pere, Noves aportacions a l'entorn del sepulcre d'Elisenda de Montcada, a Jornades de Recerca Històrica de Les Corts, Barcelona, Arxiu Municipal del Districte de les Corts, 1998, pp. 87-99.

Bofarull y Sans, Francisco de, El castillo y la Baronia d'Aramprunyà, Barcelona, Imprenta de Heinrich, 1911, pp. 96-97.

Cantarell, Elena; Comas, Mireia; Muntaner, Carme, El llibre de la Baronia d'Eramprunyà, Lleida, Pagès editors, 2011.

Cabestany, Joan-F., Aportació a la biografia de la reina Elisenda de Montcada, dins Martínez Ferrando, archivero. Miscelánea de estudios dedicados a su memoria, Madrid, Asociación Nacional de Bibliotecarios, Archiveros y Arqueólogos, 1968.

Castellano i Tresserra, Anna, Origen i formació d'un monestir femení, Pedralbes al segle XIV (1327-1411), Bellaterra, Universitat Autònoma de Barcelona, Departament de Ciències de l'Antiguitat i de l'Edat Mitjana, 1996, pp. 589-603. 
Castellano i Tresserra, Anna, Pedralbes a l'edat mitjana: història d'un monestir femení, Barcelona, Publicacions de l'Abadia de Montserrat, 1998. (Biblioteca Abat Oliba; 198).

Castellano Tresserra, Anna, Notícies documentals entorn dels vitralls, dins Els vitralls del Monestir de Pedralbes i la seva Restauració, Barcelona, Museu d'Història de Barcelona, 2011, pp. 14-15.

Castellano i Tresserra, Anna, La reina Elisenda de Montcada i el monestir de Pedralbes. Un model de promoció espiritual femenina al segle XIV, dins Garí, Blanca (ed.), Redes femeninas de promoción espiritual en los reinos peninsulares ( $s$. XIII-XVI), Roma, Viella, 2013, pp. 109131. (IRCVM-Medieval Cultures; 1 ).

Escudero i Ribot, Assumpta, Descubrimiento del palacio de la reina Elisenda en Pedralbes, dins "La Vanguardia Española", Barcelona, 7 d'abril de 1974.

Escudero i Ribot, Assumpta, El monestir de Santa Maria de Pedralbes, Barcelona, Terra Nostra, 1988.

Español, Francesca, El gótico catalan, Barcelona, Angle editorial, 2002.

Hoch, A.S., The "Passion" cycle: images to contemplate and imitate amid Clarissan clausura, dins Elliot, Janis; Warr, Cordelia (eds.), The Church of Santa Maria Donna Regina. Art, Iconography and Patronage in Fourteenth-Century Naples, Adershot, Ashgate, 2004, pp. 129-153.

Jornet, Núria, El monestir de Sant Antoni de Barcelona. L'origen i l'assentament del primer monestir de clarisses a Catalunya, Barcelona, $\mathrm{Pu}-$ blicacions de l'Abadia de Montserrat, 2007. (Scripta et Documenta; 76).

Manote, Rosa M.; Terés, Rosa, El mestre de Pedralbes i l'activitat barcelonina els anys centrals del segle XIV dins L'Art Gòtic a Catalunya, vol. I, Barcelona, Enciclopèdia catalana, 2007, pp.181-182.

Martin, Therese, Exceptions and Assumptions: Women in Medieval Art History, dins idem (ed.) Reassessing the Roles of Women as 'Makers' of Medieval Art and Architecture, vol. I, Leiden - Boston, Brill, 2012, pp. 1-33.

Martínez Ferrando, J. Ernesto, Jaime II de Aragón. Su vida familiar, Barcelona, CSIC, 1948.

Martínez Ferrando, J. Ernesto, La cámara real en el reinado de Jaime II (1291-1327). Relaciones de entradas y salidas de objectos artisticos, “Anales y Boletín de los Museos de Artes de Barcelona” 1 (19531954), pp. 168-206. 
Martorell y Trabal, Francesc, Inventari dels béns de la cambra reyal en temps de Jaume Segon (1323), "Anuari de l'Institut d'Estudis Catalans" (1911-1912), pp. 553-567.

McKiernan González, Eileen, Reception, Gender, and Memory: Elisenda de Montcada and Her Dual-Effigy Tomb at Santa Maria de Pedralbes, dins Martin, Therese (ed.), Reassessing the Roles of Women as 'Makers' of Medieval Art and Architecture, vol. I, Leiden - Boston, Brill, 2012, pp. 309-354.

Nolasco, Núria, Els atuells de fusta $i$ metall als segles XIV $i$ XV. Notes per al seu estudi, dins Del rebost a la taula. Cuina i menjar a la Barcelona gòtica, Barcelona, Museu d'Història de la Ciutat, 1995, pp. 67-70.

Nualart i Torroja, Anna, Les pintures murals negres del monestir de Pedralbes, Barcelona, Universitat de Barcelona, 2006. (Tesi doctoral).

Rius Serra, Josep, Ferrer Peyrón y el Monasterio de Pedralbes, "Analecta Sacra Tarraconensia" 13 (1937), pp. 75-77.

Rodrigues, Ana Maria S.A, The Treasures and Foundations of Isabel, Beatriz, Elisenda and Leonor, dins Martin, Therese (ed.), Reassessing the Roles of Women as 'Makers' of Medieval Art and Architecture, vol. II, Leiden - Boston, Brill, 2012 , pp. 903-935.

Rubert, C., Dos diplomas de Jaime II de Aragón referentes al monasterio de Santa María de Pedralbes, "Archivo Ibero-Americano", any XIII (juliol-desembre 1926), pp. 375-387.

Rubió, Josep; Alós, Ramon d'; Martorell, Frederic, Inventaris inèdits de l'orde del temple a Catalunya, "Anuari de l'Institut d'Estudis Catalans" (1907), pp. 385-407.

Sanjust i Latorre, Cristina, L'obra del reial monestir de Santa Maria de Pedralbes des de la seva fundació fins al s. XVI: un monestir reial per a l'ordre de les clarisses a Catalunya, Barcelona, Universitat Autònoma de Barcelona, 2010.

Sanpere i Miquel, Salvador, La pintura mig-eval catalana: l'art barbara. Discursos leidos en la Real Academia de Buenas Letras de Barcelona en la recepción publica de Salvador Sanpere y Miquel, el dia 14 de junio de 1908, Barcelona, Tip. L'Avenç, 1908.

Trens, Manuel, Ferrer Bassa i les pintures de Pedralbes, Barcelona, Institut d'Estudis Catalans, 1936.

Fecha de recepción del artículo: octubre 2013

Fecha de aceptación y versión final: mayo 2014 